\title{
Atmospheric thermal structure and cloud features in the southern hemisphere of Venus as retrieved from VIRTIS/VEX radiation measurements
}

\author{
Rainer Haus $^{\mathrm{a}^{*}}$, David Kappel ${ }^{\mathrm{b}}$, Gabriele Arnold \\ ${ }^{a}$ Westfälische Wilhelms-Universität Münster, Institute for Planetology, Wilhelm-Klemm- \\ Str.10, 48149 Münster, Germany, rainer.haus@gmx.de \\ ${ }^{\mathrm{b}}$ German Aerospace Center (DLR), Institute of Planetary Research, Rutherfordstrasse 2, \\ 12489 Berlin, Germany, dkappel@gmx.net, gabriele.arnold@ dlr.de
}

\begin{abstract}
Thermal structure and cloud features in the atmosphere of Venus are investigated using spectroscopic nightside measurements recorded by the Visible and InfraRed Thermal Imaging Spectrometer (VIRTIS) aboard ESA's Venus Express mission in the moderate resolution infrared mapping channel (M-IR, 1-5 $\mu \mathrm{m})$. New methodical approaches and retrieval results for the northern hemisphere have been recently described by Haus et al. (2013). Now, southern hemisphere maps of mesospheric temperature and cloud parameter fields are presented that cover variations with altitude, latitude, local time, and mission time. Measurements from the entire usable data archive are utilized comprising radiation spectra recorded during eight Venus solar days between April 2006 and October 2008.

Zonal averages of retrieved temperature altitude profiles in both hemispheres are very similar and give evidence of global N-S axial symmetry of atmospheric temperature structure. Cold collar and warmer polar vortex regions exhibit the strongest temperature variability with standard deviations up to $8.5 \mathrm{~K}$ at $75^{\circ} \mathrm{S}$ and $63 \mathrm{~km}$ altitude compared with about $1.0 \mathrm{~K}$ at low and mid latitudes above $75 \mathrm{~km}$. The mesospheric temperature field strongly depends on local time. At altitudes above about $75 \mathrm{~km}$, the atmosphere is warmer in the second half of night, while the dawn side at lower altitudes is usually colder than the dusk side by about $8 \mathrm{~K}$. Local minimum temperature of $220 \mathrm{~K}$ occurs at $03: 00 \mathrm{~h}$ local time at $65 \mathrm{~km}$ and $60^{\circ} \mathrm{S}$. Temperature standard deviation at polar latitudes is particularly large near midnight. Temperature variability with solar longitude is forced by solar thermal tides with a dominating diurnal component. The influence of observed cloud parameter changes on retrieved mesospheric zonal average temperature structure is moderate and does not exceed $2-3 \mathrm{~K}$ at altitudes between 60 and $75 \mathrm{~km}$. The mesospheric thermal structure was essentially stable with Julian date between 2006 and 2008 .
\end{abstract}

Global N-S axial symmetry is also observed in cloud structures. Cloud top altitude at $1 \mu \mathrm{m}$ slowly decreases from $71 \mathrm{~km}$ at the equator to $70 \mathrm{~km}$ at $45-50^{\circ}$ and rapidly drops poleward of $50^{\circ}$. It reaches $61 \mathrm{~km}$ over both poles. Average particle size in the vertical cloud column increases from mid latitudes toward the poles and also toward the equator resulting in minimum and maximum zonal average cloud opacities of about 32 and 42 and a planetary average of 36.5 at $1 \mu \mathrm{m}$. Zonal averages of cloud features are similar at different solar days, but variations with local time are very complex and inseparably associated with the superrotation of the clouds. 


\section{Introduction}

The investigation of dynamical and meteorological processes in a planetary atmosphere requires intensive studies of its thermal structure and cloud formation patterns. On Venus, especially the transition region between troposphere and mesosphere at about $60-70 \mathrm{~km}$ altitude displays a strong variability with latitude and local time both in terms of thermal structure and cloud properties. It is of special interest in atmospheric research, therefore. The Visible and InfraRed Thermal Imaging Spectrometer (VIRTIS) on Venus Express (Piccioni et al., 2007a; Drossart et al., 2007; Arnold et al., 2011; Arnold et al., 2012 ) provided an enormous amount of new data and a fourdimensional picture of the planet Venus (2D imaging + spectral dimension + temporal variations) on global scales. The spectral dimension permits a sounding of atmospheric properties at different altitude levels.

An overview of the most important past experiments in remote sensing of temperature altitude profiles and cloud features in the atmosphere of Venus has been given in the recently published companion paper by Haus et al. (2013). This paper has presented new methodical approaches and results of selfconsistent temperature profile and cloud parameter retrievals using data acquired by the moderate resolution infrared mapping channel (M-IR) of the VIRTIS instrument in the northern hemisphere. It was shown that temperature and cloud features are well separable using different spectral ranges of the $4.3 \mu \mathrm{m} \quad \mathrm{CO}_{2}$ absorption band and additional information from the $2.3 \mu \mathrm{m}$ transparency window.

It is the goal of the present paper to adapt these methods to investigations of the southern hemisphere where much more data is available compared to the northern hemisphere due to the highly eccentric orbit of VEX. Moreover, south and north results are compared and the overall cloud influence on retrieved mesospheric temperatures is estimated. Calculations of thermal winds and examinations of dynamical properties of
Venus' atmosphere in relation to global circulation models are beyond the scope of this paper. These important topics will be addressed in subsequent analyses, however.

Temperature field studies based on VIRTISM-IR data of the southern hemisphere of Venus were performed before by Grassi et al. (2010). The current investigation is completely independent from this work. It uses measurements from the full data archive (April $14^{\text {th }}, 2006$ - October $29^{\text {th }}, 2008$ ) and different methods of spectra selection and atmospheric parameter retrievals. Applying the self-consistent retrieval scheme, temperature and cloud influences on measured spectra are carefully separated to allow for explicit cloud parameter studies, which were not performed by Grassi et al.. Mean temperature and corresponding standard deviation maps as functions of local time, latitude, altitude, and data acquisition time interval are constructed and compared with results of Grassi et al. wherever possible. Additional results on latitudinal, local time, and mission time variations of cloud features are presented.

A brief summary of the method of selfconsistent temperature profile and cloud parameter retrieval is given in Section 2. Section 3 provides a description of data selection procedures taking into consideration the specific requirements of utilized simulation and retrieval procedures. Sections 4 and 5 discuss present retrieval results and how they compare to the northern hemisphere. Temperature and cloud maps are primarily produced for the full mission period of VIRTIS-M-IR (930 Earth days), but selected data sub-populations for single Venus solar days are also investigated. Section 6 contains extended discussions that comprise comparison of zonal average temperature profiles with previous findings and an estimate of cloud influence on temperature retrieval results. An interpretation of the observed temperature field with respect to thermal tides in the Venus mesosphere is also given here. The main methodical aspects and results are summarized in Section 7. 


\section{Radiative transfer simulation and retrieval techniques}

The new approach of self-consistent temperature profile and cloud parameter retrievals for Venus based on VIRTIS-M-IR data has been described in the companion paper by Haus et al. (2013). The main aspects are briefly summarized below.

A radiative transfer model (RTM), which includes the discrete ordinate package DISORT (Stamnes et al., 1988), is used to simulate measured VIRTIS-M-IR spectra recorded in the spectral range $1.0-5.1 \mu \mathrm{m}$ at about $17 \mathrm{~nm}$ resolution (FWHM). It considers absorption, emission, and multiple scattering by gaseous and particulate constituents as well as deep atmosphere $\mathrm{CO}_{2}$ continuum absorption. Look-up tables of quasi-monochromatic absorption crosssections of gaseous constituents are calculated on the basis of a line-by-line procedure for a variety of temperature and pressure values being representative for Venus' atmosphere at altitude levels between -3 and $140 \mathrm{~km}$, and for spectroscopic parameters, which are specified in Table 1 of the companion paper. Minor constituent altitude distributions are similar to that described by Pollack et al. (1993).

The newly proposed initial cloud model facilitates analytical descriptions of fourmodal particle altitude distributions where all modes are assumed to consist of spherical $\mathrm{H}_{2} \mathrm{SO}_{4}$ aerosols at 75 weight- $\%$ solution. Mie scattering theory (Wiscombe, 1980) is applied to derive wavelength-dependent microphysical parameters of each mode (absorption, scattering and extinction crosssections, single scattering albedo, asymmetry parameter, and phase function) (Haus and Titov, 2000). Log-normal size distributions are used with modal radii of $0.3,1.0,1.4$, $3.65 \mu \mathrm{m}$ and dimensionless dispersions of $1.56,1.29,1.23,1.28$, respectively (Pollack et al., 1993). Refractive index data is taken from Palmer and Williams (1975). The imaginary index gap between 1.8 and $2.9 \mu \mathrm{m}$ is filled with new measurement data provided by Carlson and Anderson (2011). The strongly changing optical depth of Venus' clouds is modeled by variation of single mode particle number densities. Introducing so-called altitude-independent cloud mode factors $\mathrm{MF}_{\mathrm{j}}$, the altitude-dependent layer optical depth may be expressed by

$$
u(z)=\sum_{j=1}^{4} M F_{j} D_{j}(z) \beta_{j}(z)
$$

where $D_{j}$ are the particle number density integrals over an atmospheric layer centered at $\mathrm{z}$, and $\beta_{\mathrm{j}}$ (in units of $\mathrm{cm}^{2}$ ) the extinction cross-sections of mode $j$, respectively. Thus, the number density of particles can be varied independently for each cloud mode, but maintaining the altitude distribution that is determined by the initial model. For all $\mathrm{MF}_{\mathrm{j}}=1.0$ and the reference wavelength $1 \mu \mathrm{m}$, the total cumulative optical depth ('cloud opacity') and the cloud top altitude $z_{t}$ that result from the initial cloud model are 35.0 and $71.3 \mathrm{~km}$, respectively. 'Cloud top altitude' is defined throughout this paper as the altitude where the cumulative optical depth at $1 \mu \mathrm{m}$ becomes unity.

In order to extract atmospheric parameters from the measurements, the RTM is embedded in a multi-window retrieval technique (MWR) that makes simultaneous use of information from different atmospheric transparency windows and absorption bands of an individual spectrum. It iteratively optimizes the parameters until the simulated radiance spectrum well fits the measurement for all utilized spectral ranges in the least-squares sense. The determined parameters are interpreted to represent the state of atmosphere that led to the observed spectrum. Dedicated spectral ranges of both the $4.3 \mu \mathrm{m} \mathrm{CO}_{2}$ absorption band and the 2.3 $\mu \mathrm{m}$ transparency window are used to disentangle influences of temperature profile (4.2-5.0 $\mu \mathrm{m}, 2000-2370 \mathrm{~cm}^{-1}$ ), cloud mode factors $\mathrm{MF}_{1,2}$ for modes 1 and 2 (3.68-3.74 $\left.\mu \mathrm{m}, 2670-2720 \mathrm{~cm}^{-1}\right)$, cloud mode factor $\mathrm{MF}_{3}$ for mode $3\left(2.2-2.3 \mu \mathrm{m}, 4350-4550 \mathrm{~cm}^{-}\right.$ $\left.{ }^{1}\right)$, and cloud upper altitude boundary $\mathrm{z}_{\mathrm{u}}$ (4.46-4.57 $\left.\mu \mathrm{m}, 2190-2240 \mathrm{~cm}^{-1}\right)$, see Figure 1 for reference. Retrieval of quantity $z_{u}$ (no cloud particles above that level) is required, since the altitude of maximum mode 2 
particle number density in the initial cloud model resides at $65 \mathrm{~km}$ (cf. Figure 4 and Table 2 in Haus et al., 2013). Even using an upper aerosol scale height close to zero in the simulations does not fit the measurements at high latitudes. Both the parameters $\mathrm{z}_{\mathrm{u}}$ and $\mathrm{MF}_{1,2}$ define the actual cloud top altitude $\mathrm{z}_{\mathrm{t}}$.

Smith's relaxation method (Smith, 1970) is applied to retrieve temperature altitude profiles from radiation measurements in the $4.3 \mu \mathrm{m} \mathrm{CO}_{2}$ band. This technique was found to produce numerically robust and reliable results (Haus and Titov, 2000; Haus 2002). It employs brightness temperatures that can be easily derived from radiance spectra using Planck's equation. The $4.3 \mu \mathrm{m}$ band theoretically sounds the altitude range of about $58-95 \mathrm{~km}$. Measured $4.3 \mu \mathrm{m}$ brightness temperatures in the main band center are very sensitive to instrumental noise (see Figure 6). This reduces the effective upper sounding altitude to $84 \mathrm{~km}$. Retrieved temperature profiles above $84 \mathrm{~km}$ are modified by a linear interpolation between 84 and $90 \mathrm{~km}$ where the $90 \mathrm{~km}$ temperature corresponds to the initial value. Initial temperature structure models (VIRA-2N) are constructed from latitude-dependent VIRA-2 temperature profiles between 50 and $90 \mathrm{~km}$ (Zasova et al., 2006b) and VIRA-1 profiles (Seiff et al., 1985) between 0 and $40 \mathrm{~km}$, which are latitude-independent below $32 \mathrm{~km}$ from the outset. Linear interpolations connect VIRA-2 values at $50 \mathrm{~km}$ and VIRA-1 values at 40 $\mathrm{km}$, and linear interpolations are also used to an assumed latitude-independent night time profile ('N') above $90 \mathrm{~km}$. The temperature is retrieved as a function of altitude $\mathrm{z}$. Since atmospheric pressure $\mathrm{p}$ is intrinsically the basic quantity for temperature calculation, $\mathrm{p}(\mathrm{z})$ is recalculated in each retrieval step using temperature and atmospheric scale height from the previous one. Initial value in the barometric formula is always the surface pressure (92.1 bar).

Retrieval of $\mathrm{MF}_{3}$ at $2.3 \mu \mathrm{m}$ requires the temperature profile at $30-40 \mathrm{~km}$ altitude as well as an initial lower cloud particle mode altitude distribution to be known. Both quantities are almost not retrievable from
VIRTIS measurements (cf. Haus et al., 2013) for argumentation with respect to temperature). The deep atmosphere temperature profile is assumed to follow the latitudinal dependence according to VIRA-1. The initial cloud model was defined by Haus et al. (2013, Figure 4, Tables 2 and 3).

Measured radiances in the atmospheric transparency windows (e.g. at $2.3 \mu \mathrm{m}$ ) are additionally strongly affected by deep atmosphere $\mathrm{CO}_{2}$ continuum absorption. This parameter has to be determined at first. MSR, a new multi-spectrum retrieval algorithm (Kappel et al., 2012; Kappel, 2014; Kappel et al., 2014) is applied. One aspect of MSR is the idea that a spectrum may be considered as a measurement of certain global atmospheric parameters (like the broadband $\mathrm{CO}_{2}$ continuum) with local variations of atmospheric structure and composition as interfering factors. In contrast to the locally varying variables, global parameters are common to all spectra. MSR is able to find simultaneous fits to many thousands spectra that originated from highly diverse physical and observational conditions on the planet.

The performance of the MWR retrieval algorithm has been investigated in detail (Haus et al., 2013) by generation of synthetic noisy spectra for different temperature profiles and cloud parameters and subsequent recovery of underlying model parameters. They are very well reproduced by the retrieval algorithm as long as the spectra are not too much disturbed by noise. The maximum absolute temperature error between 60 and $84 \mathrm{~km}$ was found to stay below $1.5 \mathrm{~K}$, while cloud mode factor deviations rarely exceed values of \pm 0.05 . It has been also demonstrated that MWR provides very good fits of measured VIRTIS spectra and is able to retrieve reliable information on physical state parameters of the atmosphere of Venus. This is exemplarily illustrated in Figure 1 for a VIRTIS-M-IR spectrum acquired on orbit $147 \_15$ at $65^{\circ} \mathrm{S}$ and local time 9:00 pm. The figure compares measurement and corresponding radiance fit in the spectral range 1.6-5.0 $\mu \mathrm{m}$ (2000-6250 $\mathrm{cm}^{-1}$ ) that encompasses the $4.3 \mu \mathrm{m} \mathrm{CO}_{2}$ band 
used for temperature retrieval as well as the 2.3 and $1.74 \mu \mathrm{m}$ atmospheric transparency windows utilized for additional cloud parameter retrievals (primarily the former one). MWR was also applied before to estimate Venus' surface emissivity (Haus and Arnold, 2010; Arnold et al., 2008; Arnold, 2011; Kappel et al., 2012).

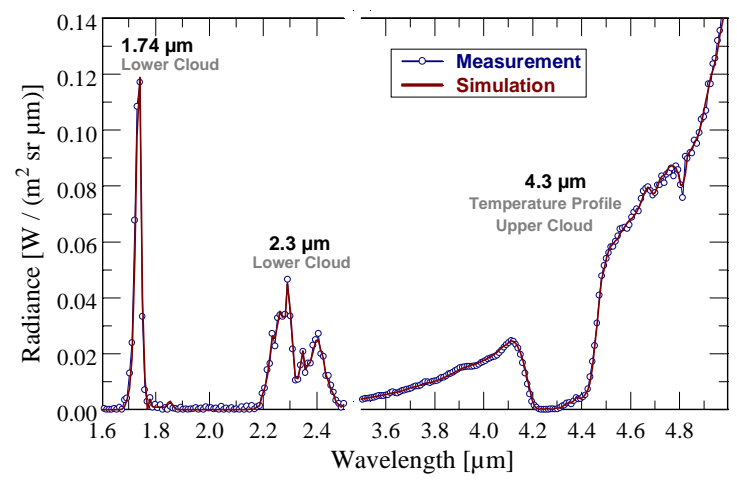

Figure 1. Comparison of VIRTIS-M-IR measurement and simulation result for one bin of orbit 0147_15 at $65^{\circ} \mathrm{S}, 09: 00 \mathrm{~h}$.

\section{Data reduction and processing}

VIRTIS-M-IR data were collected between April $14^{\text {th }}, 2006$ and October $29^{\text {th }}, 2008$. Julian date difference corresponds to about 930 Earth days, the so-called 'mission period'. A Venus solar day encompasses 116.75 Earth days. Thus, eight Venus solar days were covered by VIRTIS measurements. An elaborated data preprocessing pipeline was applied that includes refinements of data calibration procedures as well as new approaches for an effective straylight removal (Kappel et al., 2012).

The present study focuses on the southern hemisphere of Venus where apocenter mapping observations were performed. Mapping data require the use of a different binning scheme compared with that applied by Haus et al. (2013) for near-pericenter pushbroom data of the northern hemisphere. To ensure comparable statistical weights of data recorded at low and high latitudes, the measurements are sorted into bins according to a Lambert equal-area map projection such that each bin corresponds to a surface coverage of $100 \times 100 \mathrm{~km}^{2}$. For each bin, typically 30 spectra at each spectrally resolved spatially two-dimensional image were acquired by the instrument. The average over these concurrently measured spectra is computed to achieve an increase of the S/N ratio by a factor of about $5(\sim \sqrt{3} 3)$. The notations 'spectrum' or 'measurement' always refer to one of these averaged (binned) spectra in the following. The applied binning scheme yields about $5 \cdot 10^{6}$ spectra over the full mission period.

Generally, temporal and spatial variations of atmospheric features for a defined measurement time interval are sufficiently characterized by grid spacings of $\Delta \mathrm{LT}=0.5 \mathrm{~h}$ in local time (LT) direction (corresponding to 7.5 degrees subsolar longitude) and $\triangle \mathrm{LAT}=5^{\circ}$ in latitude (LAT) direction. A subsequent procedure now selects only those measurements that were recorded in the vicinity of these grid points such that the LT and LAT distances to a grid point do not exceed $0.1 \mathrm{~h}=0: 06 \mathrm{~h}$ and $1^{\circ}$, respectively. This choice of interval lengths is somewhat arbitrary, but it was used to avoid too strong basic data smoothing between adjacent main grid points. Thus, the vicinity of the grid point $\left(23: 00 \mathrm{~h}, 55^{\circ}\right)$ covers the intervals 22:54-23:06 $\mathrm{h}$ in LT direction and $49-51^{\circ}$ in LAT direction for example. The LT interval length of $0.2 \mathrm{~h}$ corresponds to $3^{\circ}$ subsolar longitude. The resulting new basic data archive can be used to study different mission time intervals, either the complete interval of eight Venus solar days or defined sub-intervals (e.g. for single Venus solar days).

VIRTIS-M-IR radiance spectra were recorded at different detector exposure times ET. It varies between 0.02 and 18 seconds. For the nightside, the majority of long exposure data was recorded at $3.3 \mathrm{~s}$, while most of short exposure data corresponds to 0.36 s. Long exposure measurements are better suited to retrieve atmospheric and surface parameters shortward of $3 \mu \mathrm{m}$, since the signal-to-noise ratio is higher than for short exposures. But unfortunately, long exposure data terminates near $4 \mu \mathrm{m}(2500$ $\mathrm{cm}^{-1}$ ) or at even shorter wavelengths due to detector saturation from dark current. 
Mesospheric temperature field investigations are based on $4.3 \mu \mathrm{m} \mathrm{CO}_{2}$ absorption band measurements. They do require the spectral region 3.8-5 $\mu \mathrm{m}$ and can only be performed using short exposure data, therefore. But also some of this data does not completely cover the spectral range up to $5 \mu \mathrm{m}$. Some other spectra show unrealistic spikes in the 3.8-5 $\mu \mathrm{m}$ range. An automatic cleaning procedure removes all these 'problem cases'.

There are two other arguments related to methodical aspects that further reduce the number of usable radiance spectra. Deep atmosphere and surface signatures (e.g. at 2.3 and $1.02 \mu \mathrm{m}$ ) are not detectable at daylight conditions, since multiple-scattering of solar radiation in the thick clouds exceeds thermal radiation by several orders of magnitude. Applied cloud parameter retrieval procedures do require information from the $2.3 \mu \mathrm{m}$ transparency window. Thus, only nightside data at sun-zenith angles larger than $98^{\circ}$ (to also exclude twilight) can be used. Moreover, the NIR spectral range shortward of $5 \mu \mathrm{m}$ strongly responses to insolation changes (cf. Figure 9 in Haus et al., 2013). Temperature retrievals from the $4.3 \mu \mathrm{m}$ band shall not utilize dayside data, therefore, since it is very difficult to discriminate between thermal radiation, scattered sunlight, and $\mathrm{CO}_{2}$ non-LTE emission features on the dayside.

Current simulation algorithms are based on a plane-parallel atmospheric model that is only justified for small and moderate observation angles (often denoted as 'emission angles', but 'observation' is more correct here). While pushbroom measurements over the northern hemisphere were performed in close-to-nadir geometry, mosaic recording over the southern hemisphere exhibited large observation angle variations. Smaller angles dominated at mid and polar latitudes, but angles up to $65^{\circ}$ often occurred at low latitudes. Spectra that were measured at observation angles larger than $60^{\circ}$ are removed from the final application archive. The need for this decision is also manifested below in the context of Figure $3 \mathrm{~b}$. Thus, the post-selection spectra population in the local time and latitude space becomes very sparse or even zero at equatorial latitudes as shown in Figure 2. It displays the distribution of spectra that were recorded over the full VIRTIS-M-IR mission period considering the required data reduction steps discussed above. Dark areas represent domains with large spectra population. Local time $-5 \mathrm{~h}$ for example stands for 5 hours before midnight, i.e. 19:00 $\mathrm{h}$. The numbers of spectra on the grid points range from zero to 1176 . The total number is about $1.4 \cdot 10^{5}$. The low spectrum population near the pole (especially near the beginning and end of night) is due to the above mentioned data restriction to sunzenith angles larger than $98^{\circ}$, because on Venus, polar regions are always close to a terminator.

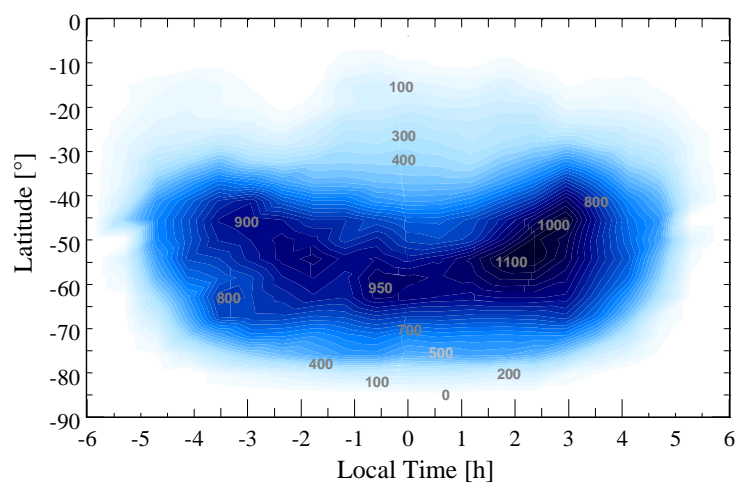

Figure 2. Post-selection spectra population in the local time and latitude space over the full mission period of VIRTIS-M-IR. Local time $-5 \mathrm{~h}$ corresponds to $19: 00 \mathrm{~h}$.

Figure 2 differs from Figure 2 presented by Grassi et al. (2010). This is due to the following reasons. Firstly, Grassi et al. restricted their study to a selection of data acquired between June 2006 and July 2008. Secondly, they considered a maximum observation angle of $30^{\circ}$ resulting in a reduction of latitude coverage (loss of 20$30^{\circ} \mathrm{S}$ for early night times, $35-45^{\circ} \mathrm{S}$ for late night times). The notations early and late night are used throughout the present paper as synonyms for the first $(18: 00 \mathrm{~h}-24: 00 \mathrm{~h})$ and second (00:00 $\mathrm{h}-06: 00 \mathrm{~h})$ half of night, respectively. Thirdly, data selection was based on a different pre-processing pipeline. Thus, the presently used final data archive extends to lower latitudes at all local times. It contains sparser spectra populations poleward of $75^{\circ} \mathrm{S}$ and local times before $-4 \mathrm{~h}$ $(20: 00 \mathrm{~h})$ and after $+4 \mathrm{~h}(04: 00 \mathrm{~h})$, however. 
The utilized algorithms of simultaneous temperature altitude profile and cloud parameter retrieval require significant computing time. It is almost impossible, therefore, to process tens of thousands of individual spectra, and statistically reasonable spectra selections have to be performed in advance. For interpretation of results, retrieved temperature profiles and cloud parameters shall be averaged and the corresponding standard deviations shall be calculated. This can be done in various ways. One can apply a random selection of $\mathrm{N}$ spectra at each grid point of the local time and latitude space. But statistically representative results are only obtained when $\mathrm{N}$ is sufficiently large. Present investigations use a special spectra pre-selection method as described below.

Brightness temperature (BT) is the basic quantity used for temperature retrieval according to the applied Smith relaxation method. With respect to the wavenumberspecific altitude distributions of temperature weighting functions (Haus et al., 2013), BT changes at certain parts of the spectrum translate to temperature profile changes at corresponding altitude ranges in the same order of magnitude. Figure 3a shows simulated brightness temperature spectra ( $45^{\circ}$ latitude, initial cloud model) for two observation angles of 0 and $65^{\circ}$. Maximum differences between the curves reach about 8 K. Retrieval procedures consider the actual value of observation angle of an individual spectrum, and the results are largely angleindependent, therefore. But when spectra averaging, subsequent calculation of spectra standard deviations, and the definition of 'permitted' spectrum variability (see text below) are intended prior to retrieval calculations, it is very important to estimate the range of possible BT changes due to observation angle variation and to determine limits for angle variations that keep BT changes as small as possible. If this kind of investigation was neglected, it may happen that calculated BT standard deviations are not determined by real atmospheric variations, but are strongly masked by large observation angle variations as shown in
Figure 3a. Real variations of retrieved temperature profiles and cloud parameters are strongly underestimated in this case.

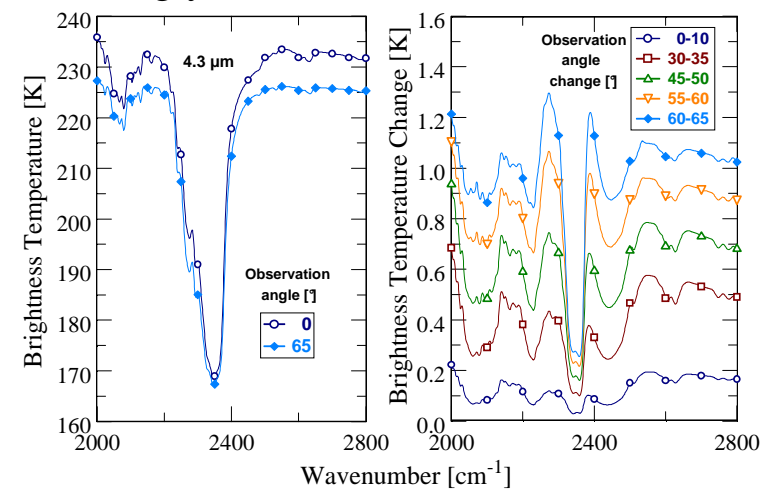

Figure 3. a) Simulated brightness temperature spectra at $45^{\circ} \mathrm{S}$ for observation angles $0^{\circ}$ and $65^{\circ}$. b) Change of simulated brightness temperatures in the $4.3 \mu \mathrm{m}$ spectral range (2000-2800 $\left.\mathrm{cm}^{-1}\right)$ for observation angle variations over the ranges $0-10,30-35,45-50,55-60$, and $60-65^{\circ}$.

Figure $3 \mathrm{~b}$ illustrates the maximum change of simulated brightness temperatures in the 4.3 $\mu \mathrm{m}$ spectral range $\left(2000-2800 \mathrm{~cm}^{-1}\right)$ for observation angle changes over indicated intervals. BT changes resulting from small angle variations around nadir $\left(0-10^{\circ}\right)$ are small and do not exceed $0.2 \mathrm{~K}$. For fixed angle variation $\left(5^{\circ}\right.$ in the investigated cases), BT changes increase with increasing absolute angle and reach values up to $1.3 \mathrm{~K}$ in the near wings of the band for an angle variation from 60 to $65^{\circ}$. Much larger BT changes would occur for $5^{\circ}$ observation angle variations at angles larger than $65^{\circ}$. Variations caused by 10 degrees or larger steps would of course increase BT changes up to the extreme case of $8 \mathrm{~K}$ as shown in Figure 3a. In summary, it can be concluded that spectra averaging should be restricted to measurements where the observation angles do not differ by more than $5^{\circ}$ except for close to nadir sounding. The discussion also clearly indicates that spectra that were recorded at observation angles above $60^{\circ}$ should not be used to avoid possible temperature profile errors larger than $1 \mathrm{~K}$.

As a prerequisite for the spectra averaging procedure described below, the histogram of spectrum distribution for $5^{\circ}$ observation angle intervals $\left(10^{\circ}\right.$ close to nadir $)$ is determined, and the interval for maximum 
spectrum population is selected. This is demonstrated exemplarily in Figure 4, which refers to measurements acquired at $59-61^{\circ} \mathrm{S}$ and 23:54-00:06 $\mathrm{h}$. While initial angles range from $2.1-56.4^{\circ}$, only spectra corresponding to the prevailing observation angle of $20-25^{\circ}$ (i.e. 219 spectra) are considered at this grid point further on. This way, each grid point exhibits a specific 'optimum' spectrum population within one of the observation angle intervals ranging from $0-10^{\circ}$ to $55-60^{\circ}$, and the total spectrum number for all local time and latitude grid points in the total mission time interval reduces to 32866 . Considering this reduced spectrum number, the two-dimensional distribution still resembles the plot shown in Figure 2.

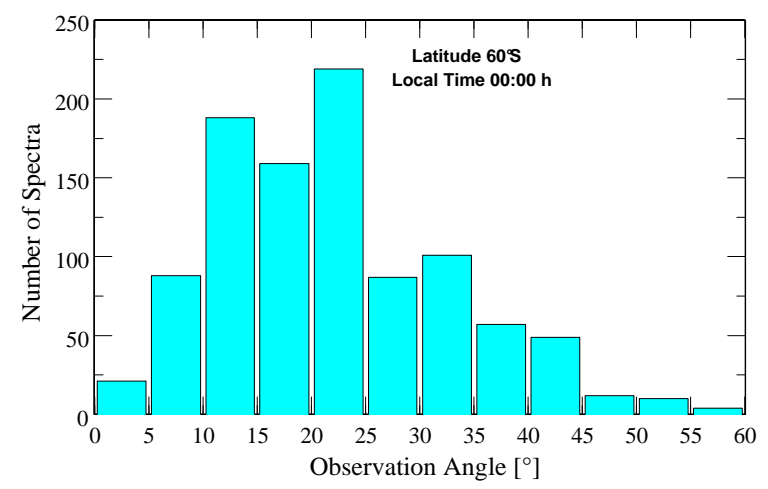

Figure 4. Histogram of spectrum distribution with observation angle.

Once the prevailing observation geometry is defined for all grid points (' $\mathrm{GP}_{\mathrm{k}}$ ') of the local time and latitude space, statistically representative spectra are selected. For this purpose, an initial brightness temperature spectrum averaging at each wavenumber $v$ in the vicinity of the $4.3 \mu \mathrm{m}$ band (2000-2800 $\mathrm{cm}^{-1}$ ) is performed at first. The resulting $\mathrm{B}_{v}{ }^{\text {mean }}$ spectrum is an artificial one, however, since it is based on a simple arithmetic mean. Due to the involved non-linearities it may not represent a realizable spectrum at all. A real mean spectrum $\mathrm{B}_{v}{ }^{\text {mean* }}$ is additionally determined therefore as the actually measured spectrum that is in the leastsquares sense the closest to $\mathrm{B}_{v}{ }^{\text {mean }}$ over the full spectral range of the $4.3 \mu \mathrm{m}$ band and its periphery $\quad\left(2000-2800 \quad \mathrm{~cm}^{-1}\right) . \quad \mathrm{B}_{v}{ }^{\text {mean* }}$ represents a measured average state of the atmosphere at $\mathrm{GP}_{\mathrm{k}}$.
The spectrum $\mathrm{B}_{v}{ }^{\text {mean }}$ is now used to calculate brightness temperature standard deviations $\sigma_{v}$. Plots of $\sigma_{v}$ for three latitude grid points $\left(30,60,80^{\circ} \mathrm{S}\right)$ at $00: 00 \mathrm{~h}$ are depicted in Figure 5. Brightness temperature deviations roughly translate to temperature profile differences at a certain altitude. Measured brightness temperature variations in the 4.3 $\mu \mathrm{m}$ band wings are mainly determined by temperature profile changes at altitudes 55$80 \mathrm{~km}$, while variations in the center range (at about 2250-2400 $\mathrm{cm}^{-1}, 4.17-4.44 \mu \mathrm{m}$ ) arise from temperature changes at higher altitudes up to $90 \mathrm{~km}$. Neglecting possible changes of cloud features at this point (the band wings are sensitive to both temperature and cloud features), one can expect maximum temperature profile differences at $30^{\circ} \mathrm{S}$ and 00:00 $\mathrm{h}$ that do not exceed 10-12 K near $70 \mathrm{~km}$ altitude for the used $\pm 2 \sigma_{v}$ brightness temperature selection. Expected maximum temperature profile differences at $60^{\circ} \mathrm{S}$ and $55-70 \mathrm{~km}$ are in the order of $16 \mathrm{~K}$. Very large temperature fluctuations up to about $30 \mathrm{~K}$ in the same altitude region may occur at $80^{\circ} \mathrm{S}$.

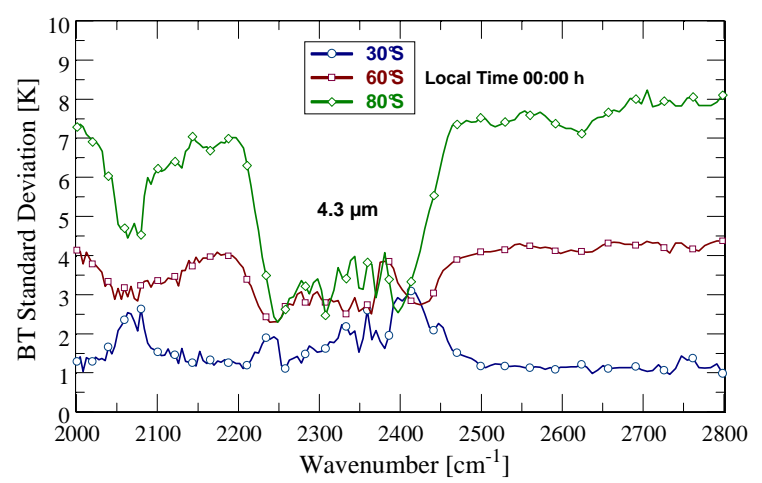

Figure 5. Brightness temperature standard deviations in the $4.3 \mu \mathrm{m}$ band as functions of wavenumber for different latitudes.

Sub-population BT fields $\mathrm{B}_{v}$ at each $\mathrm{GP}_{\mathrm{k}}$ are specified in the next step, which comprise all elements that lie within $\pm 2 \sigma_{v}$ from $\mathrm{B}_{v}{ }^{\text {mean }}$ at each wavenumber (i.e. about $95 \%$ of basic spectra at $\mathrm{GP}_{\mathrm{k}}$ assuming normal distribution). Finally, some auxiliary spectra are selected from the $\mathrm{B}_{v}$ fields that shall explore the data variability at different spectral sub-ranges within the $4.3 \mu \mathrm{m}$ band. They comprise the minimum and maximum spectra appearing in both band wings and the near center range (six spectra). An example is depicted in 
Figure 6 for the grid point at 00:00 $\mathrm{h}$ and $60^{\circ} \mathrm{S}$, where 100 spectra are available as result of the $\pm 2 \sigma_{v}$ selection (thin lines). Solid circles mark the real measured spectrum $\mathrm{B}_{v}{ }^{\text {mean* }}$. Minimum and maximum (real) measurements in the left wing are signalized by empty triangles down and up. To ensure that the full variability of cloud opacity is considered in the retrievals, two additional spectra are selected that correspond to minimum and maximum measurements in the $2.3 \mu \mathrm{m}$ transparency window (inset in Figure 6). They are marked by solid triangles down and up. Obviously, they do not introduce special prominent spectral features at $4.3 \mu \mathrm{m}$, however. In the same way, the $\mathrm{min} / \mathrm{max}$ spectra at $4.3 \mu \mathrm{m}$ are not prominent at $2.3 \mu \mathrm{m}$. This hints at the statistical independency of 4.3 and $2.3 \mu \mathrm{m}$ features. Note that only four of the eight auxiliary spectra are highlighted in the figure. The other four ensure that spectrum variability is considered everywhere in the $4.3 \mu \mathrm{m}$ range (e.g. in the near wing at around $2400 \mathrm{~cm}^{-1}$ ). It can happen that a point in the local time and latitude space has a very sparse spectra population. As a consequence, some of the eight auxiliary spectra may become identical.

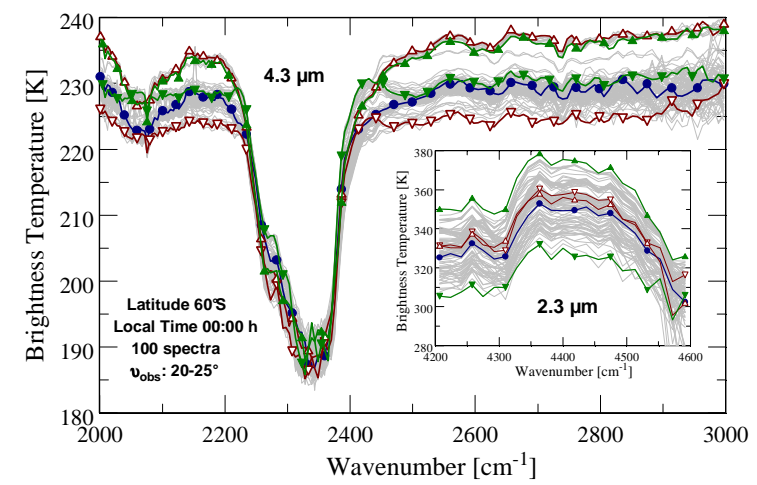

Figure 6. Spectra sub-populations at 4.3 and $2.3 \mu \mathrm{m}$ $\left(\mathrm{B}_{v}{ }^{\text {mean }} \pm 2 \sigma_{v}\right)$. Solid circles: mean (really measured) spectrum $\mathrm{B}_{v}{ }^{\text {mean* }}$. Empty triangles down and up: one set of minimum/maximum spectra in the $4.3 \mu \mathrm{m}$ band wings. Solid triangles down and up: minimum /maximum spectra in the $2.3 \mu \mathrm{m}$ transparency window.

Operational retrieval calculations are finally performed using the above specified nine individual spectra at each grid point of the local time and latitude space. This may in the worst case require a maximum of 4050 individual retrieval runs (18 latitudes $0-85^{\circ}$, 25 local times 18-6 h, nine spectra) for each selected data acquisition time interval (eight single solar days and total period). Mean spectra $\mathrm{B}_{v}{ }^{\text {mean* }}$ define the most probable temperature profiles and cloud features at time and location of the measurements, while all nine selected spectra are used to explore typical parameter variations at that grid point.

\section{Temperature results}

Mesospheric temperature altitude profiles in the southern hemisphere of Venus are retrieved as functions of latitude, local time, and time interval of data acquisition (mission period). The applied binning and data reduction procedures and subsequent mean and auxiliary spectra selections are identical for all mission time intervals. Two additional parameters in the procedures define minimum and maximum boundary of the actually used acquisition time interval. Retrieval results can be sorted into different kinds of two-dimensional maps where temperatures are sampled either "vertically" (as functions of latitude and altitude at fixed local times and as functions of local time and altitude at fixed latitudes, respectively) or "horizontally" (as functions of local time and latitude at fixed altitude levels of the atmosphere).

Recall that retrieved temperature profiles above $84 \mathrm{~km}$ are modified by linear interpolations, which connect the retrieved temperature at $84 \mathrm{~km}$ with the initial value at $90 \mathrm{~km}$. This is required due to the noisy features of measured radiances in the main $4.3 \mu \mathrm{m}$ band center, which is the only range where temperatures at altitudes above $84 \mathrm{~km}$ can be retrieved from.

\subsection{Zonal average}

The zonal average (i.e. average over local time) of the atmospheric temperature field is investigated at first considering the full mission period. This provides the opportunity to compare actual results for the southern hemisphere with recently published findings for the northern hemisphere (Haus et al., 
2013). Local time averaging is performed over the night time interval [19:00 h, 05:00 h]. Figure 7 displays the zonal average of mean temperature field as a function of latitude and altitude in both hemispheres. South mean temperatures result from processing of mean spectra $\mathrm{B}_{v}{ }^{\text {mean* }}$ as described in Section 3. Values between 0 and $10^{\circ} \mathrm{S}$ and also at $85^{\circ} \mathrm{S}$ are extrapolated due to lacking data coverage (cf. Figure 2). Temperature data for the northern hemisphere is taken from Haus et al. (2013). North temperatures were retrieved from 34 'pushbroom' orbits using local time averaged measurements at each latitude grid point from the outset.

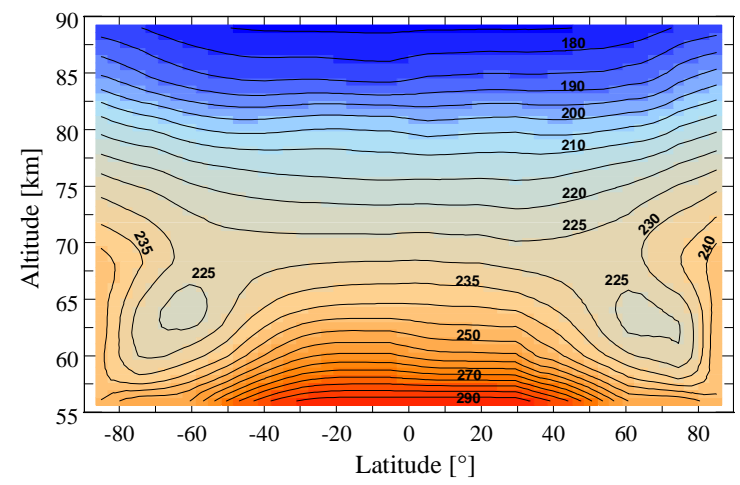

Figure 7. Zonal average of mean temperature field as a function of latitude and altitude in both hemispheres. Temperatures are given in $\mathrm{K}$.

Southern hemisphere temperature features represent almost a mirror image of the northern hemisphere. The similarities between northern and southern hemisphere indicate global N-S axial symmetry of atmospheric temperature structure. Figure 8 shows zonal averages of mean temperatures between 55 and $85 \mathrm{~km}$ in $5 \mathrm{~km}$ steps as functions of latitude. There are two narrow altitude ranges near 85 and $60 \mathrm{~km}$ where the symmetry seems to be slightly disturbed. At $85 \mathrm{~km}$, southern temperatures are about $2 \mathrm{~K}$ lower at all latitudes compared with northern values. Higher temperatures are found in the southern hemisphere at around $60 \mathrm{~km}$ with hemispheric differences between 2 and $4 \mathrm{~K}$ where the larger differences are observed at low latitudes. Complete correspondence between southern and northern temperatures at $55 \mathrm{~km}$ is due to the fact that temperature weighting functions are very small below about $58 \mathrm{~km}$ causing retrieved values to largely follow the initial VIRA profiles (Haus et al., 2013).

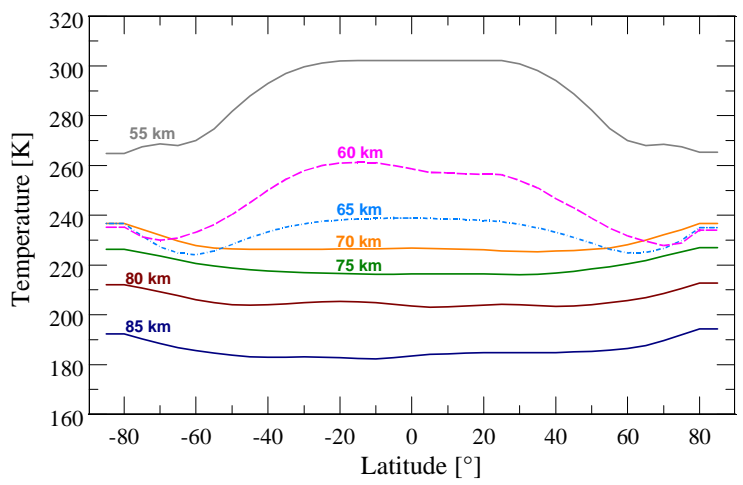

Figure 8. Zonal averages of mean temperatures as functions of latitude at selected altitudes.

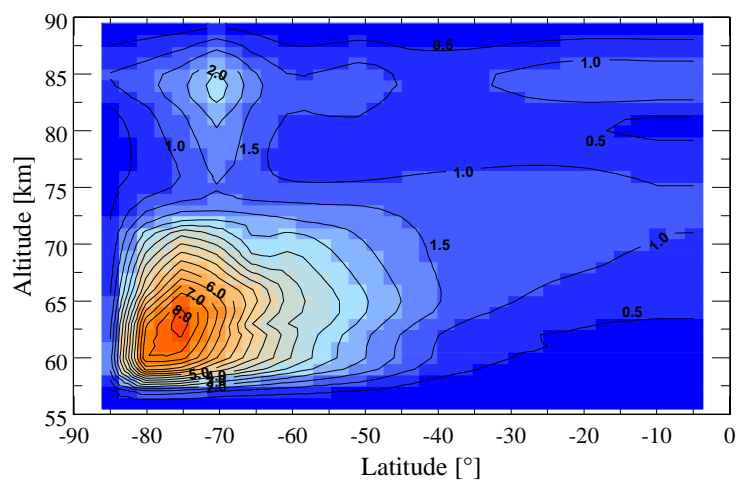

Figure 9. Zonal average of temperature standard deviations $[\mathrm{K}]$ as a function of latitude and altitude in the southern hemisphere.

Figure 9 illustrates the zonal average of temperature variability as a function of latitude and altitude for the southern hemisphere. The depicted values are the standard deviations $\sigma_{\text {Tza }}$ calculated from retrieved temperatures for the nine spectra that are processed at each grid point in the local time and latitude space and subsequently averaged over local time (denoted by ' $z a$ '). Collar and vortex regions exhibit the strongest temperature variability with values of $\sigma_{\text {Tza }}$ up to $8 \mathrm{~K}$ at $75^{\circ} \mathrm{S}$ and 63 $\mathrm{km}$. This may correspond to maximum absolute temperature variations of about 30 $\mathrm{K}$. Much less temperature variability of about $\sigma_{\mathrm{Tza}}=1 \mathrm{~K}$ (maximum absolute difference $4 \mathrm{~K}$ ) is observed at low and mid latitudes. The nine temperature altitude profiles at 30 and $75^{\circ} \mathrm{S}$ (zonal averages) are visualized by thin lines in Figure 10. The thick lines with solid boxes correspond to the mean temperature profile obtained from the $\mathrm{B}_{v}{ }^{\text {mean* }}$ spectrum. Maximum and minimum temperature values 
at each altitude are marked by solid triangles. The initial temperature profiles (VIRA-2N) are also shown for comparison. Retrieved mean temperatures at both latitudes are slightly lower than VIRA temperatures. While the "auxiliary" temperature profiles, which are retrieved from the eight auxiliary spectra described in Section 3, scatter around the VIRA profile at $75^{\circ} \mathrm{S}$, they are generally somewhat lower than VIRA at $30^{\circ} \mathrm{S}$ (and generally at low latitudes).

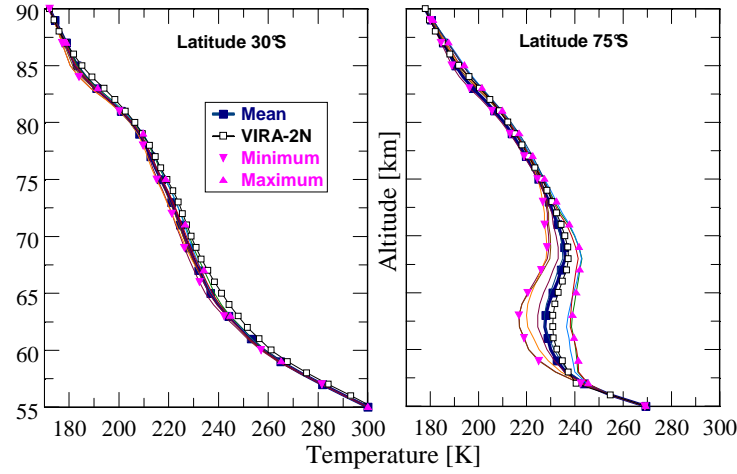

Figure 10. Zonal averages of mean and auxiliary temperature altitude profiles at 30 and $75^{\circ} \mathrm{S}$.

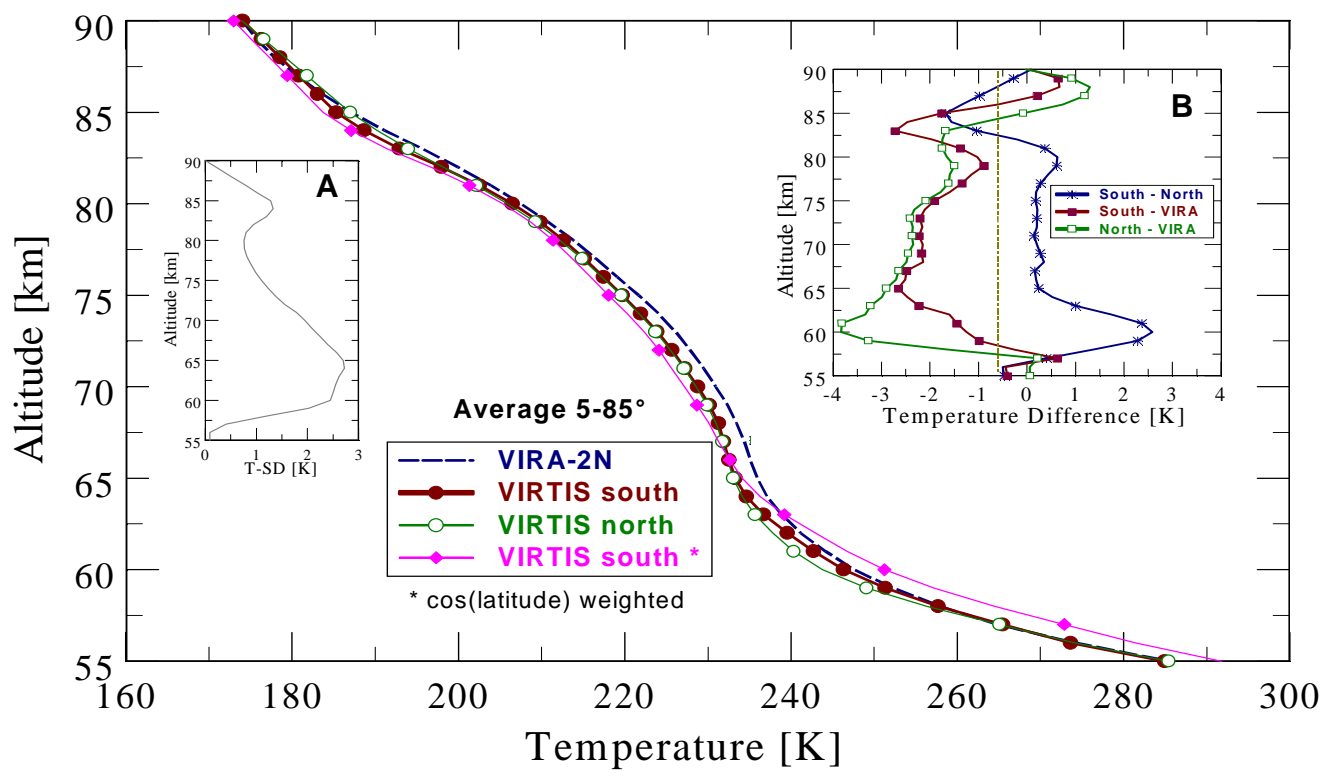

Figure 11. Hemispheric averages over temperature profiles in comparison with VIRA-2N profile. Inset A: Hemispheric average of temperature standard deviation VIRTIS south. Inset B: Temperature differences as indicated.

Figure 11 compares the hemispheric averages $\mathrm{T}_{\mathrm{H}}(\mathrm{z})$ over retrieved temperature profiles from all processed VIRTIS spectra in both hemispheres with the hemispheric average of VIRA-2N profiles. $\mathrm{T}_{\mathrm{H}}(\mathrm{z})$ is calculated according to equation (2),

$T_{H}(z)=\frac{\int_{\varphi_{1}}^{\varphi_{2}} T_{z a}(z, \varphi) W(\varphi) d \varphi}{\int_{\varphi_{1}}^{\varphi_{2}} W(\varphi) d \varphi}$

where $\mathrm{T}_{\mathrm{za}}(\mathrm{z}, \varphi)$ is the altitude $\mathrm{z}$ and latitude $\varphi$ dependent (zonal average) temperature profile and $\mathrm{W}(\varphi)$ is the used latitude weighting function. The calculation of the hemispheric (or planetary) average of atmospheric local time and latitude dependent temperature altitude profiles is useful, since it describes the typical mean temperature structure of a planetary atmosphere. Such a mean profile can be utilized, for example, to perform initial (onedimensional) studies on atmospheric radiative energy balance.

The north average differs from Figure 31 shown by Haus et al. (2013) where weighted averages in the latitude interval $\left[\varphi_{1}, \varphi_{2}\right]=$ $\left[30^{\circ} \mathrm{N}, 80^{\circ} \mathrm{N}\right]$ were calculated using spectrum numbers at each latitude as the weights. Due to the almost constant number of spectra obtained from VIRTIS-north pushbroom data at all latitudes in this interval, the weights have practically no influence, however. The new 'north curve' shown in Figure 11 is based on the unweighted average $(\mathrm{W}(\varphi)=1.0)$ of temperature altitude profiles for $\left[\varphi_{1}, \varphi_{2}\right]=$ 
$\left[5^{\circ} \mathrm{N}, 85^{\circ} \mathrm{N}\right]$ to correspond to the scheme applied to obtain the present 'south curve'. The extended latitude range $\left(5-85^{\circ}\right.$ instead of $30-80^{\circ}$ ) ensures a better representation as 'hemispheric average'. The new 'north curve' has lost its slight inversion near $65 \mathrm{~km}$ due to the additional influence of near equatorial latitudes that are characterized by smoother temperature altitude profiles (cf. Figure 10). When radiative energy balance investigations are performed, however, a weighting with $|\cos (\varphi)|$ should be used as depicted for the southern hemisphere by the curve marked with solid diamonds. The correspondence between north and south curves is very good, and differences are less than $1 \mathrm{~K}$ between 63 and $83 \mathrm{~km}$ as shown in inset B (recall also text concerning Figure 7). A maximum difference of $2.5 \mathrm{~K}$ occurs at 60 $\mathrm{km}$. The average northern hemisphere temperature at $85 \mathrm{~km}$ is $1.7 \mathrm{~K}$ larger than the southern one as it was already discussed in the context of Figure 8. Inset B also shows temperature differences between VIRTISSouth/North and VIRA-2N. Absolute values are mostly below $2.5 \mathrm{~K}$ in both hemispheres with a general trend to slightly lower north temperatures below $82 \mathrm{~km}$. There is a maximum difference of $3.8 \mathrm{~K}$ at $60 \mathrm{~km}$. Differences between north results and VIRA are slightly larger than reported by Haus et al. (2013), but this is again due to the extended latitude range and especially due to the influence of low latitudes as mentioned in the context of Figure 10. Inset A in Figure 11 shows the hemispheric average of temperature standard deviation in case of VIRTIS south. Maximum values of 2-3 K occur between 60 and $70 \mathrm{~km}$. There is a local maximum of $1.3 \mathrm{~K}$ at $85 \mathrm{~km}$. Comparing insets $\mathrm{A}$ and $\mathrm{B}$, it follows that temperature differences between VIRTIS south and VIRA on the one hand and temperature standard deviation of the VIRTIS south result on the other hand have a similar scale over the full altitude range. In other words, differences between the hemispheric average curve south at its upper standard deviation boundary $\left(\mathrm{T}_{\mathrm{H}}{ }^{\text {VIRTIS }}+\sigma_{\mathrm{H}}{ }^{\text {VIRTIS }}\right.$ ) and the hemispheric average of VIRA temperatures $T_{H}{ }^{\text {VIRA }}$ would not exceed $1 \mathrm{~K}$.
Due to the rather sparse VIRTIS data distribution over the northern hemisphere, results for the southern hemisphere are regarded to be more reliable. They are also closer to the hemispheric average of the VIRA profiles and closer to temperature results obtained from processing Venera-15 PMV data (cf. Haus et al., 2013, Figure 31), especially at around $60 \mathrm{~km}$. Comparison with PMV data in favor of reliability of VIRTIS results may not appear to be convincing, since PMV data covered the northern hemisphere and are separated by about 23 years from VIRTIS measurements. A direct comparison of retrieval results (see Section 6.1) seems to justify this argument, however.

\subsection{Local time and solar day dependence}

Figure 12 displays mean atmospheric temperature fields as functions of latitude and altitude for LT 00:00 h (a) and 03:30 h (b). Mean temperatures are based on processing of mean spectra $\mathrm{B}_{v}{ }^{\text {mean* }}$. Latitude is restricted to the interval $\left[15-80^{\circ} \mathrm{S}\right]$ where data is mostly available between 19:00 and 05:00 h (cf. Figure 2). The plots resemble the zonal average shown in Figure 7. Principal structures of the mesospheric temperature field (poleward temperature decrease below about $67 \mathrm{~km}$ with inversion at high latitudes down to $57 \mathrm{~km}$ and poleward increase above about $70 \mathrm{~km}$ ) do not change with local time, but some time-specific variations are observed (e.g. at $65^{\circ} \mathrm{S} / 65 \mathrm{~km}$ and $70^{\circ} \mathrm{S} /$ $80-85 \mathrm{~km})$. The region of the cold collar (latitudes $50-75^{\circ} \mathrm{S}$ and altitudes $62-68 \mathrm{~km}$ ) exhibits the strongest changes with local time. This is illustrated in more detail in $\underline{\text { Figure } 13}$ where mean temperature fields are shown as functions of local time and altitude for $65^{\circ} \mathrm{S}$ (a) and $75^{\circ} \mathrm{S}(\mathrm{b})$, respectively. Solid circles and boxes shall facilitate comparison of Figures 12-14. The temporal development of the cold collar region at altitudes below $68-70 \mathrm{~km}$ is clearly discernible in both displays. While the collar is not very pronounced in the first half of night with temperatures of $230 \mathrm{~K}$ at $65^{\circ} \mathrm{S} / 64 \mathrm{~km}$ and $232 \mathrm{~K}$ at $75^{\circ} \mathrm{S} / 62 \mathrm{~km}$, the atmosphere cools down at late night. Temperature in the collar 


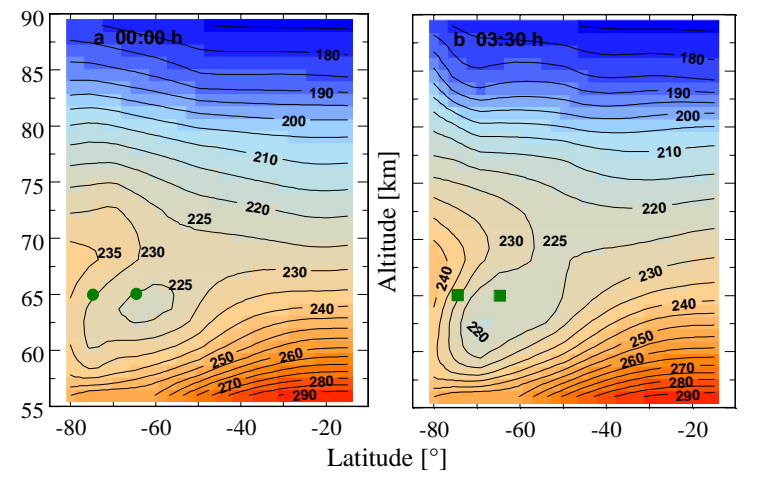

Figure 12. Mean temperature fields as functions of latitude and altitude at local times 00:00 h (a) and 03:30 h (b). Temperatures are given in K. Symbols mark grid points that are also shown in Figures 13 and $14 \mathrm{a}$.

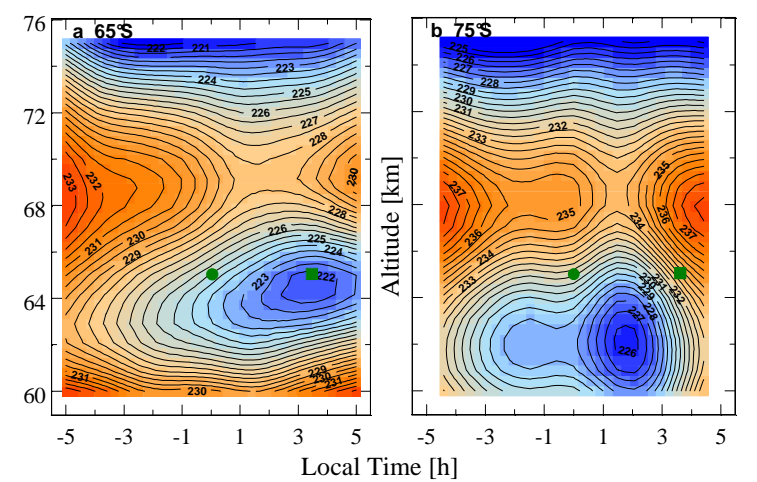

Figure 13. Mean temperature fields as functions of local time and altitude at latitudes $65^{\circ} \mathrm{S}$ (a) and $75^{\circ} \mathrm{S}$ (b). Temperatures are given in $\mathrm{K}$. Local time $-5 \mathrm{~h}$ corresponds to 19:00 h. Symbols mark grid points that are also shown in Figures 12 and 14a.

center at $65^{\circ} \mathrm{S}$ reaches a minimum of $220 \mathrm{~K}$ at $03: 30 \mathrm{~h}$. The center minimum at $75^{\circ} \mathrm{S}(225$ $\mathrm{K}$ ) is located $2 \mathrm{~km}$ lower and occurs about $1.5 \mathrm{~h}$ earlier $(02: 00 \mathrm{~h})$. Note that the displays in Figures 12 and 13 represent temperature results obtained from mean spectra $\mathrm{B}_{v}{ }^{\text {mean* }}$. Individual temperature profiles retrieved from the eight auxiliary spectra at each local time and latitude grid point may deviate from mean profiles as shown in Figure 10 for zonal averages, but the general trends with local time and latitude are preserved, nonetheless. Similar behavior of atmospheric temperatures with solar time at latitudes between 75 and $85^{\circ}$ was reported by Tellmann et al. (2009, Figure 14) from the $\mathrm{VeRa/VEX}$ radio occultations. A direct comparison with present Figure $13 b$ is difficult, however, due to the used latitude average in the Tellmann results. Their temperature minimum at about $64 \mathrm{~km}$ resides at midnight, while the minimum at $75^{\circ} \mathrm{S}$ in present findings occurs at 02:00 $\mathrm{h}$. This is further discussed in Section 6.3.

Presentation of atmospheric temperatures as functions of local time and latitude at different altitudes is another option to investigate temporal changes of the thermal structure. This is exemplarily shown in Figure 14 for altitudes of $65 \mathrm{~km}$ (a) and 80 $\mathrm{km}$ (b). Displays $\mathrm{c}$ and $\mathrm{d}$ describe corresponding temperature differences from the average temperature field (Figure 7). As a first general statement it can be concluded that absolute differences between mean local time dependent and mean zonal average nightside temperatures do not exceed $5 \mathrm{~K}$ at the same local time and latitude. This corresponds well to Figures 3a, 3d, 4a, and $4 \mathrm{~d}$ in the paper of Grassi et al. (2010).

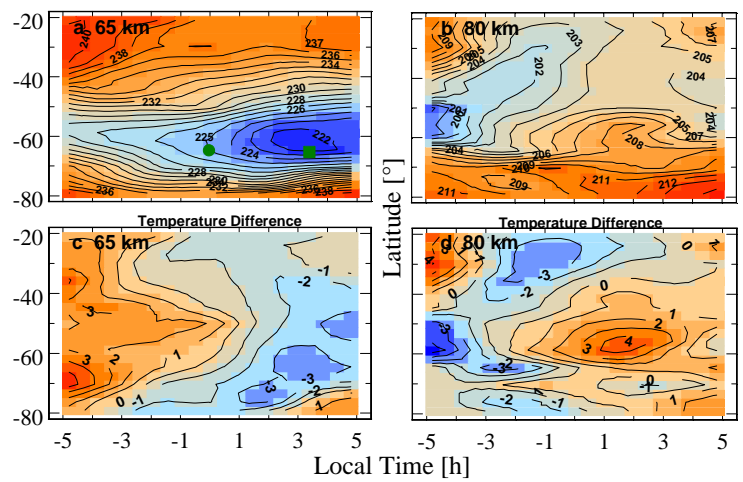

Figure 14. Mean temperature fields as functions of local time and latitude at altitudes $65 \mathrm{~km}$ (a) and 80 $\mathrm{km}$ (b). Displays (c) and (d) show corresponding differences between local time dependent and local time averaged mean temperatures. Temperatures are given in K. Local time $-5 \mathrm{~h}$ corresponds to 19:00 $\mathrm{h}$. Symbols in display (a) mark grid points that are also shown in Figures 12 and 13.

Near $65 \mathrm{~km}$ and equatorward of $75^{\circ} \mathrm{S}$, the atmosphere is warmer at early night and colder at late night. The $0 \mathrm{~K}$ isoline in the temperature difference map (Figure 14c) fluctuates around midnight between 45 and $65^{\circ} \mathrm{S}$, but it is located near 21:00 h at low and high latitudes. Toward the end of night, polar latitude temperatures tend to increase again. The high variability of the cold collar region centered near $65^{\circ} \mathrm{S}$ at this altitude is well documented by Figure 14a. Keeping in mind that only mean temperatures are visualized in the plots, the temperature decreases from 232 
$\mathrm{K}$ at 19:00 $\mathrm{h}$ to $221 \mathrm{~K}$ at $03: 00 \mathrm{~h}$ and remains almost constant during the rest of night.

Near $80 \mathrm{~km}$ and poleward of $45^{\circ} \mathrm{S}$, the atmosphere is colder at early night and warmer at late night, thus showing a reversed trend compared with $65 \mathrm{~km}$. Strongest temperature changes occur between 50 and $60^{\circ} \mathrm{S}$ with local minima and maxima of 198 and $209 \mathrm{~K}$ at 19:00 $\mathrm{h}$ and 02:00 $\mathrm{h}$, respectively. Equatorward of $45^{\circ} \mathrm{S}$, a cell of warmer air (up to $211 \mathrm{~K}$ at $30^{\circ} \mathrm{S}$ ) is observed at early night, which cools down to $202 \mathrm{~K}$ at 23:00 h. As in case of more southern latitudes, temperature then increases toward the end of night. Thus, present results do not completely confirm the finding of Grassi et al. (2010) that the morning hemisphere is in general the warmer one at $80 \mathrm{~km}$ altitude. But this holds true at latitudes southward of $45^{\circ} \mathrm{S}$ where Grassi results are restricted to. Present results also indicate that temperatures at this altitude do not monotonically increase toward the south at every local time.

Figure 15 shows temperature standard deviation fields $\sigma_{\mathrm{T}}$ as functions of local time and latitude for the same altitudes used in Figure 14 ((a) $65 \mathrm{~km}$, (b) $80 \mathrm{~km}$ ). $\sigma_{\mathrm{T}}$ is calculated from retrieved temperatures $\mathrm{T}_{\mathrm{i}}$ from the nine spectra that are processed at each grid point. These results correspond very well to Figure 5 shown by Grassi et al.. $\sigma_{\mathrm{T}}$ is particularly large at $65 \mathrm{~km}$ (display a) at high latitudes $\left(70-80^{\circ} \mathrm{S}\right)$ in the first two thirds of night and reaches maximum values of about $9 \mathrm{~K}$ near midnight (see also Figure 9 (present paper) where zonal averages of temperature standard deviation are plotted). $\sigma_{\mathrm{T}}=9 \mathrm{~K}$ may correspond to maximum absolute temperature variations in the order of $35 \mathrm{~K}$. The plot for $60 \mathrm{~km}$ (not shown here) looks similar. This remarkable variability is due to the presence of the strongly changing eye of the polar vortex (Luz et al., 2011). Temperature variability is also large in the region of the cold collar, which extends northward to about $55-60^{\circ} \mathrm{S}$. $\sigma_{\mathrm{T}} \sim 4 \mathrm{~K}$ at $60^{\circ} \mathrm{S}$ corresponds well to the temperature variability of $16 \mathrm{~K}$ roughly estimated from brightness temperature standard deviations discussed in the context of Figure 5.
Latitudes northward of $40^{\circ} \mathrm{S}$ at all local times are characterized by small temperature variability with $\sigma_{\mathrm{T}}$ values usually in the order of 1.0-1.5 K, thus being smaller than expected values (up to $3 \mathrm{~K}$ ) shown in Figure 5 for $30^{\circ} \mathrm{S}$. An additional $\sigma_{\mathrm{T}}$ feature in Figure 15 is the weak variability at late night at all latitudes southward of about $40^{\circ} \mathrm{S}$. Recall that previous performance tests of the MWR retrieval algorithm (Haus et al., 2013) have indicated that the maximum absolute error of retrieved temperature profiles between 60 and $84 \mathrm{~km}$ is less than $1.5 \mathrm{~K}$. Thus, determined temperature standard deviations below this value are less significant.

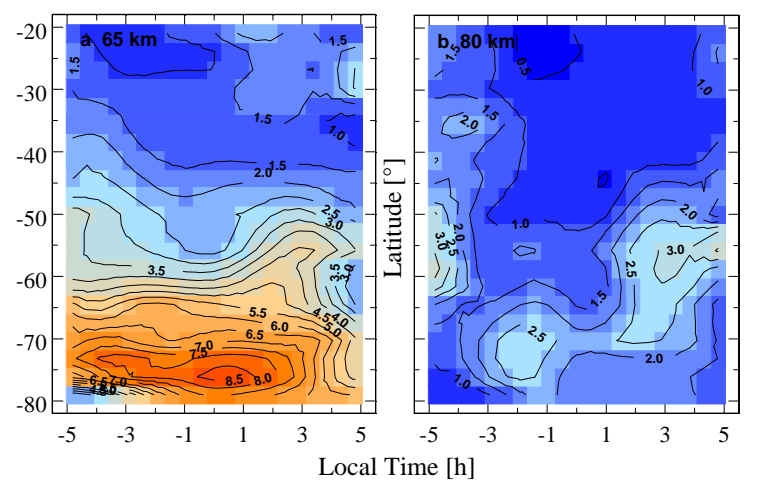

Figure 15. Temperature standard deviation fields as functions of local time and latitude at altitudes $65 \mathrm{~km}$ (a) and $80 \mathrm{~km}$ (b). Values are given in K. Local time $5 \mathrm{~h}$ corresponds to 19:00 h.

At $75 \mathrm{~km}$ (not shown here), the temperature variability is generally very weak at all latitudes and local times with $\sigma_{\mathrm{T}}$ values usually not exceeding $1.5 \mathrm{~K}$. Variability slightly increases at $80 \mathrm{~km}$ (display b) and latitudes southward of $50^{\circ} \mathrm{S}$, but only in some isolated local time domains. Standard deviations at $80 \mathrm{~km}$ are generally smaller by about $2 \mathrm{~K}$ than values reported by Grassi et al. (2010).

It is important to mention here that the partly large standard deviations do not contradict the results with respect to discussed temperature trends. Absolute temperature values may change within $\pm 2 \sigma_{\mathrm{T}}$ ranges, but calculated temperature differences (see Figure $14 \mathrm{c}$ and d) are not strongly affected, since both local time dependent and local time averaged values are influenced by the same $\sigma_{\mathrm{T}}$, which is not a strongly varying function of local time. 
It is also worth pointing out here the relative smoothness of temperature variations with latitude and local time as displayed in Figures 12-15. This provides an a posteriori verification of the utilized data selection procedure where mesospheric temperature field variations have been assumed to be sufficiently characterized by grid spacings of $\Delta \mathrm{LT}=0.5 \mathrm{~h}$ in local time direction and $\triangle \mathrm{LAT}=5^{\circ}$ in latitude direction (see Section $3)$.

The retrieval of local time and latitude dependent mesospheric temperature altitude profiles from VIRTIS/VEX-M-IR measurements is one of the main goals of the present paper. Figure 16 shows mean air temperature profiles at selected local times for latitudes $30,45,65$, and $75^{\circ} \mathrm{S}$. For reason of readability, only the altitude range between 60 and $85 \mathrm{~km}$ is displayed. Table 3 in the Appendix lists the underlying data for $50-100 \mathrm{~km}$.

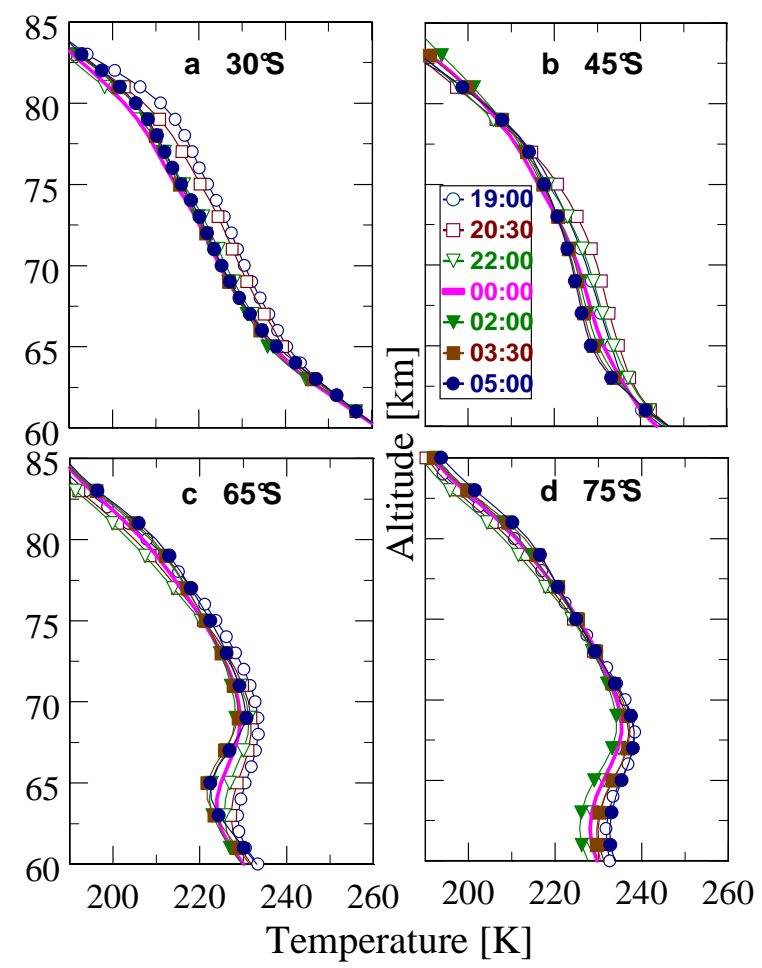

Figure 16. Mean air temperature profiles at selected local times for latitudes $30,45,65$, and $75^{\circ} \mathrm{S}$.

Eight Venus solar days were covered by VIRTIS-M-IR measurement data. Grid point populations in the local time and latitude space vary with mission period. Temperature profile retrievals reveal no significant changes of results for different solar days. The atmosphere at $65 \mathrm{~km}$ altitude and all latitudes is warmer on the dusk side and colder on the dawn side over the course of all days (or more precisely all nights). Singleday temperatures are partly lower and partly higher than total mission period values, but the differences never exceed a few K. An explicit temperature trend with mission time is not observed, neither with respect to local time nor with respect to latitude and altitude. Thus, it can be concluded that the single-day averaged mesospheric thermal structure was essentially stable with Julian date between 2006 and 2008. This stands in marked contrast to $\mathrm{SO}_{2}$ abundance variations as observed by Marcq et al. (2011; 2013). The authors reported on a general two-fold $\mathrm{SO}_{2}$ increase at cloud top levels in the 2006-2008 time frame in the northern hemisphere and an episodic much stronger increase in early 2007, while a $\mathrm{SO}_{2}$ decrease by an order of magnitude occurred between 2008 and 2012.

\section{Cloud parameter results}

The method to retrieve parameters of Venus' clouds has been extensively described in the companion paper by Haus et al. (2013), and a summary was given in Section 2 of the present paper. The cloud top altitude and upper cloud layer opacities are mainly determined by the composition and altitude distribution of smaller particles that belong to modes 1 and 2. Mode 1 aerosols play a minor role at IR wavelengths. They are nonetheless treated together with mode 2 aerosols. Changes of cloud opacities are modeled by variations of cloud mode factors $\mathrm{MF}_{\mathrm{j}}$ leaving the initial (latitude independent) cloud mode altitude distribution functions unvaried. Applying the self-consistent temperature profile and cloud parameter multi-window retrieval algorithm (MWR) it was found that very small (down to almost zero) mode factors $\mathrm{MF}_{1,2}$ are required to fit the strong brightness temperature inversion features at about $4.51 \mu \mathrm{m}\left(2190-2240 \mathrm{~cm}^{-1}\right)$ that are mainly observed at mid and polar latitudes. On the other hand, such extremely small factors do not match adjacent wing spectral 
ranges of the $4.3 \mu \mathrm{m} \mathrm{CO}$ band especially near $3.71 \mu \mathrm{m}\left(2670-2720 \mathrm{~cm}^{-1}\right)$ where $\mathrm{MF}_{1,2}$ is determined from. $\mathrm{MF}_{1,2}=0.2$ turned out to be the possible lower limit. The altitude of maximum mode 2 particle number density in the initial cloud model resides at $65 \mathrm{~km}$. Using the initial model and the factor $\mathrm{MF}_{1,2}=0.2$, the cloud top altitude $\left(\mathrm{z}_{\mathrm{t}}\right)$ at $85^{\circ} \mathrm{S}$ and $1 \mu \mathrm{m}$ is $65.4 \mathrm{~km}(60.7$ at $4.51 \mu \mathrm{m})$, which is definitely too high to fit the corresponding measurements. As a consequence, the present retrieval scheme includes an additional loop for cloud upper altitude boundary ( $\mathrm{z}_{\mathrm{up}}$, no cloud particles above that) retrieval at $4.51 \mu \mathrm{m}$. Recall that cloud top altitude and cloud opacity are wavelength-dependent quantities. Cloud top altitude is retrieved at about $4.5 \mu \mathrm{m}$. Referencing to an arbitrary wavelength (1 $\mu \mathrm{m}$ in the present paper) is easily feasible assuming that all four cloud modes belong to $\mathrm{H}_{2} \mathrm{SO}_{4}$ aerosols and applying Mie scattering theory to derive the wavelength-dependent microphysical parameters as pointed out in Section 2.

Supplemental performance tests of the MWR retrieval algorithm have been performed after the companion paper has been published. Much more synthetic noisy spectra for different temperature profiles and cloud parameters have been generated, and the subsequent recovery of underlying model parameters allowed new estimates of methodical retrieval errors. The uncertainty of retrieved cloud mode factors $\mathrm{MF}_{1,2}$ and $\mathrm{MF}_{3}$ is in the order of 0.05 with sometimes lower values towards equatorial latitudes. A variation of both $\mathrm{MF}_{1,2}$ and $\mathrm{MF}_{3}$ by +0.05 results in an opacity variation at $1 \mu \mathrm{m}$ of about 1.75 and 1.45 at $0^{\circ}$ and $85^{\circ}$, respectively. The latitude dependence is due to cloud top altitude differences. Lower $\mathrm{z}_{\mathrm{t}}$ at polar latitudes (cf. Section 5.1) reduce the column number density of mode 1 and 2 particles compared with the initial model and thus the opacity response to mode factor changes. Uncertainties of $\mathrm{z}_{\text {up }}$ retrievals are in the order of $1 \mathrm{~km}$ for latitudes poleward of $50^{\circ}$. They may increase up to $5 \mathrm{~km}$ at low latitudes where inversion features in the brightness temperature spectra at $4.51 \mu \mathrm{m}$ are more or less absent. These large $\mathrm{z}_{\mathrm{up}}$ errors at low latitudes are less critical than they seem to be at first view, however, since they lead to $\mathrm{z}_{\mathrm{t}}$ changes of no more than $300 \mathrm{~m}$. This is due to the assumed exponential decrease of mode abundance altitude distribution functions in the initial model with a mode 2 scale height of $3.5 / 3.0 \mathrm{~km}$ above/below 65 km (cf. Table 2 in Haus et al., 2013). Combined with a possible $\mathrm{MF}_{1,2}$ error of $0.05, \mathrm{z}_{\mathrm{t}}$ may change up to $500 \mathrm{~m}$. A $\mathrm{z}_{\text {up }}$ error of $+1 \mathrm{~km}$ at $75^{\circ} \mathrm{S}$, on the other hand, would increase $\mathrm{z}_{\mathrm{t}}$ by about $1.2 \mathrm{~km}$. Combined with a $\mathrm{MF}_{1,2}$ increase of $0.05, \mathrm{z}_{\mathrm{t}}$ increases by 1.5 $\mathrm{km}$. Note that $z_{u p}$ and $z_{t}$ are not linked in a linear relationship. The influence of comparatively small $\mathrm{z}_{\text {up }}$ uncertainties of $1 \mathrm{~km}$ is larger at polar latitudes, since retrieved $\mathrm{z}_{\mathrm{up}}$ values are in the order of $66-64 \mathrm{~km}$ here. A sharp upper cloud boundary at $65 \mathrm{~km}$ for example causes the mode 2 particle number distribution function to lose roughly one half of its altitude integral value, since the distribution function peaks at $65 \mathrm{~km}$. A $z_{u p}$ difference of $1 \mathrm{~km}$ is very significant, therefore.

Summarizing this error discussion it can be stated that the cloud top altitude retrieval error varies from about $0.5 \mathrm{~km}$ at the equator to about $1.5 \mathrm{~km}$ at the pole. Mode factor retrieval errors are in the order of 0.05 , while opacity errors may reach 1.75 at the equator and 1.45 at polar latitudes (about $4 \%$ on the average, cf. Figure 18).

\subsection{Zonal average}

As in case of temperature retrievals, zonal averages of mean cloud features as functions of latitude are presented at first considering the full mission period. Figure 17 displays the zonal average of mean values of cloud top altitude $\mathrm{z}_{\mathrm{t}}$ at $1 \mu \mathrm{m}$ as function of latitude for both hemispheres. The mean south curve in Figure 17 results from processing of mean spectra $B_{v}{ }^{\text {mean* }}$ as described in Section 3. $z_{t}$ data for the northern hemisphere is taken from Haus et al. (2013). 'South' scatter points around step $5^{\circ}$ latitude grid points reflect retrieval results for the nine 
investigated spectra at every local time, 'north' scatter points correspond to results obtained from analysis of 34 pushbroom orbits. The broken line at $71.3 \mathrm{~km}$ indicates the $z_{t}$ value of the initial cloud model. The two thin solid lines show the above discussed retrieval error range boundaries referred to the mean curve.

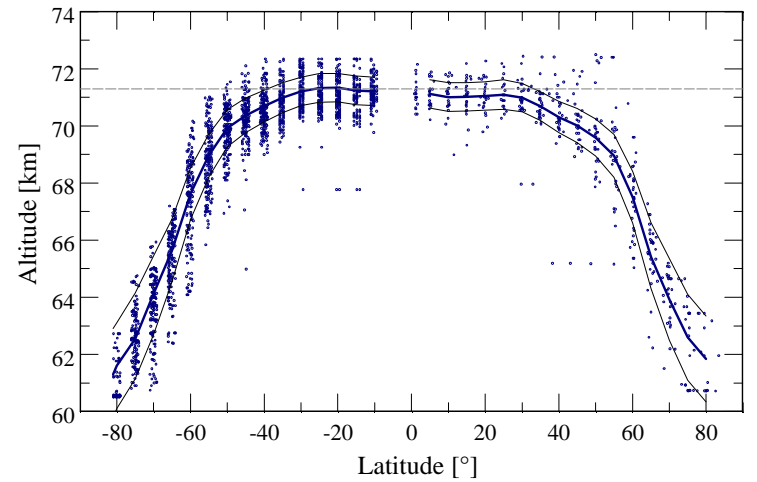

Figure 17. Zonal average and scatter of mean cloud top altitude at $1 \mu \mathrm{m}$ as functions of latitude in both hemispheres. Thin solid lines: Retrieval error range boundaries referred to the mean curve.

Zonal averages of cloud top altitude in the southern hemisphere very closely match the north results. The main differences between south and north occur at low and mid latitudes with slightly larger values in the south (up to $0.4 \mathrm{~km}$ ). There is a slow decrease of cloud top altitude from about 71 $\mathrm{km}$ at the equator to about $70 \mathrm{~km}$ at $45-50^{\circ}$. $\mathrm{z}_{\mathrm{t}}$ quickly drops poleward of $50^{\circ}$ and reaches about $61 \mathrm{~km}$ over both poles. Apart from few outliers, southern low and high latitude top altitudes vary by about 2.5 and $3.5-4.0 \mathrm{~km}$, respectively, and even higher deviations from the mean curve occur at mid latitudes. Depicted variations are largely due to retrieval uncertainties, while remaining changes beyond the indicated retrieval error range boundaries may be due to real variations of the cloud deck, but also due to a limited sensitivity of measurements. Actual findings are in good correspondence with earlier results (Zasova et al., 2006a; Ignatiev et al., 2009; Lee et al., 2012) including observed scatter. This was already discussed in the companion paper by Haus et al. (2013).

Variations of zonal averages of mean cloud top altitude with Venus solar day are found to be smaller than $0.6 \mathrm{~km}$. This is much smaller than variations described by the scatter plots. Thus, the above discussed decrease of cloud top altitude with increasing latitude is a generic feature of Venus' atmosphere.

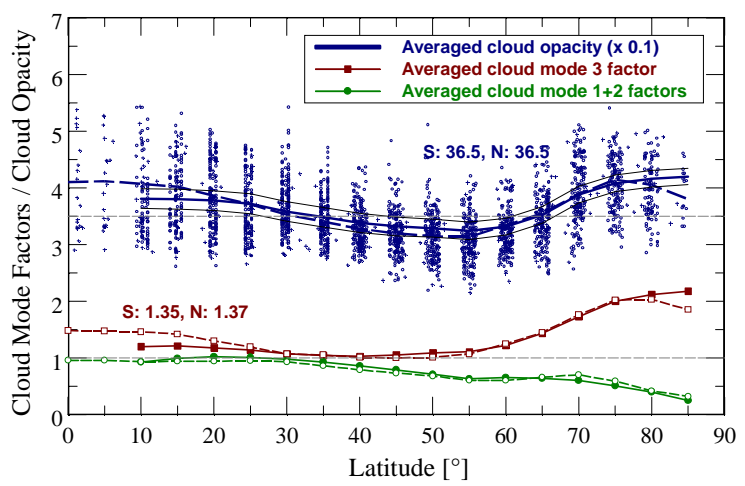

Figure 18. Zonal averages of cloud mode factors $\mathrm{MF}_{1,2}, \mathrm{MF}_{3}$ and cloud opacity $(1 \mu \mathrm{m})$ as functions of latitude in both hemispheres. Solid lines/symbols: southern hemisphere (S). Broken lines/empty symbols: northern hemisphere $(\mathrm{N})$. Numbers near the curves: cloud factors and opacity for unweighted hemispheric averages (5-85 ${ }^{\circ}$ south/north). Circles and crosses scatter points: Opacity scatter south/north. Thin solid lines: Retrieval error range boundaries referred to the mean opacity curve south.

Figure 18 shows zonal averages of mean values of total cloud optical depth (opacity at $1 \mu \mathrm{m}$ ),-cloud mode factor $\mathrm{MF}_{1,2}$, and cloud mode factor $\mathrm{MF}_{3}$ as functions of latitude. The general latitude dependence is very similar in both hemispheres. As in case of temperature fields and cloud top altitudes, this indicates an almost global N-S axial symmetry of cloud structure. Existing differences, on the other hand, are not surprising, since the fast rotating cloud cover of Venus is known to exhibit irregular and streaky shapes especially at low and mid latitudes (Titov et al., 2012). The reliability of an average over strongly time-dependent cloud features depends on the number of measurements, which is much larger over the southern hemisphere. The numbers near the curves denote opacity and cloud factor results for the hemispheric averages for latitudes $5-85^{\circ}$ south/north. Both the values for opacity and mode factors are nearly identical in the two hemispheres. This seems to be a rather random result however, since the south-north differences obviously compensate each other. The broken lines at ordinate values 3.5 and 
1.0 correspond to 35.0 for cloud opacity and 1.0 for cloud mode factors and are given by the initial cloud mode altitude distribution model. Note that the displayed opacities are multiplied by a factor of 0.1 .

There is a strong latitude dependence of cloud opacity, which is related to the latitudinal behavior of cloud mode factors. Corresponding to the initial model, larger particles have much stronger influence on cloud absorption and scattering features than small particles have. At equatorial latitudes up to $30^{\circ}$, retrieved mode 1 and 2 factors $\left(\mathrm{MF}_{1,2}\right)$ in both hemispheres are fairly constant with values close to the initial ones and south values slightly larger than north values. $\mathrm{MF}_{1,2}$ gradually decrease poleward of $30^{\circ}$ showing a small local minimum at $55^{\circ}$. The local maximum at $70^{\circ}$ is only present in the north data. The mode 3 factors $\left(\mathrm{MF}_{3}\right)$ are nearly constant up to about $15^{\circ}$ (1.20 south, 1.45 north), decrease between 15 and $30^{\circ}$, remain almost constant up to $55^{\circ}$, but then strongly increase poleward. The combined influence of $\mathrm{MF}_{1,2}$ and $\mathrm{MF}_{3}$ is reflected in the latitudinal behavior of opacity with larger values compared with the initial one equatorward of $30-35^{\circ}$ and poleward of $65^{\circ}$ and lower values at intermediate latitudes. $\mathrm{MF}_{1,2}$ and $\mathrm{MF}_{3}$ factors have a value close to 1.0 at $30-35^{\circ}$, and the cloud opacity attains its initial value 35 here. Opacity is minimal near $55^{\circ}$. The drop northward of $75^{\circ} \mathrm{N}$ is most likely not a real feature, but due to few measurement data (see Figure 1 in Haus et al., 2013). It is reasonable to assume that a large opacity in the order of the $75^{\circ}$ value is also present at the North Pole as it is the case at the South Pole. Recall that the uncertainty of single retrieved cloud mode factors is in the order of 0.05 , while opacity errors vary between 1.45 and 1.75 (about $4 \%$ on the average).

The present analyses reveal that the average particle size in the vertical cloud column increases from mid latitudes toward the poles. This corresponds to the findings by Wilson et al. (2008) and Lee et al. (2012) who identified larger particles in the south polar atmosphere of Venus. Analyzing
Galileo NIMS data (Grinspoon et al., 1993) the authors concluded that mode 3 particle abundance variations represent the dominant source of observed opacity variations in the lower and middle clouds, and that the total cloud optical depth varies between 25 and 40. The spatial and temporal coverage of NIMS measurements was comparatively small because of the short duration of the Venus flyby. VIRTIS observations yield a zonal average opacity range between 32 and 42 with a possible range extension to about 30.5 and 43.5 according to the two thin solid lines that show the above discussed retrieval error range boundaries referred to the mean opacity curve. Observed single spectrum opacity variations are significantly larger than the estimated retrieval errors. This is plausible due to the high temporal variability of cloud features.

Since the concentration of larger particles also increases from mid latitudes toward equatorial latitudes, it can be concluded that equatorial and polar latitudes are covered by thicker clouds than mid latitudes between 30 and $60^{\circ}$. The hemispheric (unweighted) average of cloud opacity derived from VIRTIS data in both hemispheres is 36.5 at 1 $\mu \mathrm{m}$. The corresponding cloud mode factors are about $\mathrm{MF}_{1,2}=0.75$ and $\mathrm{MF}_{3}=1.35$. The three parameters are regarded as planetary averages. These numbers slightly differ from those reported by Haus et al. (2013) for the northern hemisphere where latitude averages were based on weighted averages in the range $30-80^{\circ} \mathrm{N}$. When a weighting of latitude $\varphi$ dependent cloud parameters is used where the weights correspond to $|\cos (\varphi)|$, the southern hemispheric averages of opacity and the two mode factors are 36.0, 0.86, and 1.21 , respectively. The changes in the three parameters compared with unweighted averages reflect the weaker influence of high latitudes.

\subsection{Local time and solar day dependence}

Figure 19 visualizes the local time dependence of mean cloud top altitudes $\left(\mathrm{z}_{\mathrm{t}}\right)$ for the southern hemisphere considering the 
full mission period of measurements. Differences between local time dependent and local time averaged results are shown for selected latitudes. At low latitudes northward of $40^{\circ} \mathrm{S}$, cloud top altitudes decrease at early night and reach minima near 23:00 h. They increase in the second half of night, but morning values are slightly lower than evening values. Changes are in the order of 1 $\mathrm{km}$. Less than $0.5 \mathrm{~km}$ variability occurs at 60 and $80^{\circ} \mathrm{S}$. In contrast, nocturnal $\mathrm{z}_{\mathrm{t}}$ changes of about $2 \mathrm{~km}$ are observed at 50 and $70^{\circ} \mathrm{S}$ with a distinct maximum at $22: 00 \mathrm{~h}$ and $70^{\circ} \mathrm{S}$. The curves imply that the overall variability of $\mathrm{z}_{\mathrm{t}}$ with latitude and local time is very complex. In most cases, variations with local time are below the retrieval uncertainties shown in Figure $17\left(\mathrm{z}_{\mathrm{t}}\right.$ variations of about $\pm 0.5 \mathrm{~km}$ at the equator and about $\pm 1.5 \mathrm{~km}$ at the pole). Thus, the specification of certain cloud top altitude trends with local time from VIRTIS nightside measurements is not possible. It should be mentioned here that local time variations of $z_{t}$ on the dayside were reported to stay below $\pm 1.0 \mathrm{~km}$ (Ignatiev et al., 2009; Cottini et al., 2012).

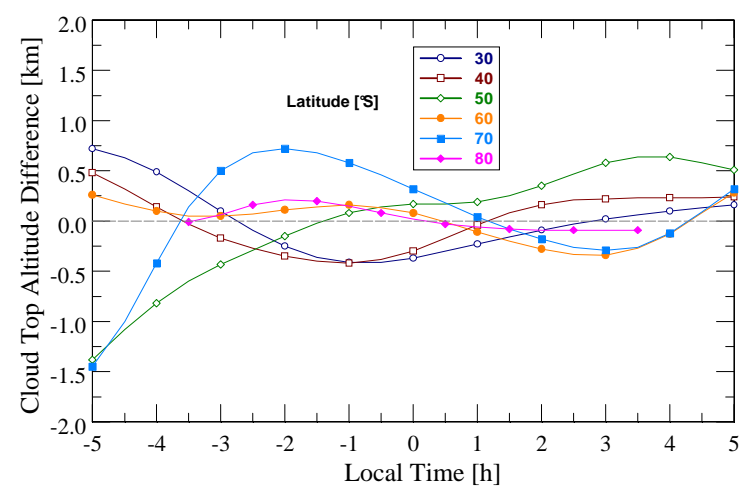

Figure 19. Differences between local time dependent and local time averaged mean cloud top altitude at 1 $\mu \mathrm{m}$ as functions of local time for selected latitudes. Values are given in $\mathrm{km}$.

The specific patterns of cloud top altitude variation with local time may strongly change when the investigated data acquisition time interval is reduced to single solar days while corresponding zonal averages are well compatible. This is not surprising, however, since morphology and dynamical state of clouds at their top level are highly variable both on short and long time scales as it was observed by the Venus Express Monitoring Camera (VMC, e.g.
Titov et al., 2012). It is supposed, however, that the total measurement time interval of eight solar days yields the most representative view (in the sense of statistical stability) of cloud top variation with local time. Nevertheless, a systematic trend with local time as retrieved by Zasova et al. (2006a, 2007) from Venera-15 PMV measurements over the northern hemisphere is not reflected in the VIRTIS data.

Cloud opacity is the most vigorously varying state parameter of Venus' atmosphere. Low latitudes are covered by clouds that are relatively dark at an UV wavelength of 365 $\mathrm{nm}$ with a strongly fragmented appearance. While mid latitudes show more streaky features, high latitudes poleward of about $60^{\circ}$ are characterized by a bright polar hood, which is sometimes scattered by darker spiral or circular structures (Titov et al., 2012). Not only with respect to latitude, but also regarding local time and mission period, the cloud formation patterns are very complex. Partly adverse features are observed at NIR wavelengths in dependence on latitude as detailed maps of opacity as functions of local time and latitude for different solar days have shown. This is mainly due to the well-known superrotation of the cloud cover, which encircles the planet in about four Earth days. Calculation of opacity for fixed local times (i.e. averaging of data recorded on different orbits at different Julian dates) and the presentation of such maps would not be very reasonable, therefore. On the other hand, zonal averages of cloud opacity for different measurement data acquisition times emphasize that the principal features discussed in the context of Figure 18 are maintained.

\section{Discussion}

\subsection{Comparison of zonal average temperature profiles}

The main features of the retrieved zonal average temperature field in both hemispheres correspond to previous results from Pioneer Venus Infrared Radiometer 
(Taylor et al., 1980) and Venera-15-PMV data (Zasova et al., 2006a; 2007; northern hemisphere) and also well agree with previous analyses of VIRTIS-M-IR (Grassi et al., 2010) data from the southern hemisphere (see Table 1 below). For fixed altitudes, temperatures are nearly constant at low latitudes (equatorward of $30^{\circ}$ ). While temperatures below $57 \mathrm{~km}$ monotonically decrease poleward of $30^{\circ}$, they tend to increase above about $70 \mathrm{~km}$ poleward of 40$50^{\circ}$. The poles are colder than the equator by about $40 \mathrm{~K}$ at $55 \mathrm{~km}$, but warmer by about $10-15 \mathrm{~K}$ at high altitudes above $70 \mathrm{~km}$. The two principal temperature domains at low and high altitudes are separated by cells of colder air that are located at latitudes between 50 and $75^{\circ}$ and altitudes between 58 and $70 \mathrm{~km}$. They form the well-known 'cold collar' regions. The warmer and vertically nearly isothermal regions poleward of $75^{\circ}$ that extend from 58 to $66 \mathrm{~km}$ are also striking features of Venus' temperature field. Temperatures near $60 \mathrm{~km}$ and some $2-3 \mathrm{~km}$ below, however, may reach $250 \mathrm{~K}$ poleward of $70-75^{\circ}$. Such hot, rotating, highly variable, and partly double-eyed brightness temperature structures over the poles were observed in both hemispheres (e.g. Taylor et al., 1979; Piccioni et al., 2007b). These vortex features are sometimes called 'hot (or polar) dipole'. Real dipole features were seen very rarely during the VEX mission, however (Limaye et al., 2009). Luz et al. (2011) and Titov et al. (2009) also showed polar eye morphologies quite different from a dipole.

Table 1 compares retrieved temperatures for selected latitudes and altitudes obtained by five groups of authors denoted by A-E in the table. The correspondence between A (Haus et al., this work) and B (Grassi et al., 2010) is extremely good, although different retrieval methods are applied. Both A and B values are based on VIRTIS-M-IR nightside data south. Local time averages A encompass the interval [19:00-05:00 $\mathrm{h}$ ] and $\mathrm{B}$ the interval [19:00-03:00] (see B, Figure 8). Unfortunately, B does not cover altitudes below $65 \mathrm{~km}$ and latitude $30^{\circ} \mathrm{S}$. Maximum temperature difference of $2 \mathrm{~K}$ is found at $65^{\circ} \mathrm{S}$ and $70 \mathrm{~km}$.

Table 1. Comparison of retrieved temperatures at selected latitudes and altitudes. Temperature is given in $\mathrm{K}$. References A-E: see text.

\begin{tabular}{l|cccc|cccc|cccc}
\hline $\begin{array}{l}\text { Latitude } \\
{\left[{ }^{\circ}\right]}\end{array}$ & \multicolumn{3}{|c|}{30} & \multicolumn{3}{c|}{65} & & & 75 \\
\hline $\begin{array}{l}\text { Altitude } \\
{[\mathrm{km}]}\end{array}$ & 60 & 65 & 70 & 80 & 60 & 65 & 70 & 80 & 60 & 65 & 70 & 80 \\
A & 258 & 237 & 226 & 204 & 231 & 224 & 230 & 208 & 231 & 231 & 234 & 211 \\
B & - & - & - & - & - & 224 & 228 & 209 & - & 230 & 235 & 212 \\
C & 255 & 235 & 224 & 189 & 232 & 224 & 231 & 205 & 232 & 232 & 234 & 205 \\
D & 261 & 245 & 230 & 193 & 250 & 220 & 228 & 215 & 245 & 218 & 229 & 218 \\
E & 245 & 232 & 217 & 189 & 225 & 228 & 228 & 201 & 228 & 233 & 232 & 204 \\
\hline
\end{tabular}

Temperature data $\mathrm{C}$ in Table 1 is taken from Zasova et al. (2006b, Figure 12; 2007, Figure 5) and is based on Venera-15 PMV measurements performed over the northern hemisphere. Zonal averages encompass night and day conditions. The agreement between $\mathrm{A}$ and $\mathrm{C}$ is again very good and typically within 1-3 K. Larger deviations are partly found at $80 \mathrm{~km}$. This is a remarkable result in three respects. First, it indicates N-S axial symmetry of atmospheric temperature structure as already stated above while discussing Figure 7. Second, it underlines that atmospheric temperatures at fixed latitude and averaged over local time on the day- and nightside of Venus below $100 \mathrm{~km}$ are very similar (cf. discussion with respect to Figure 7 in Haus et al., 2013). Third, the good conformance of $\mathrm{A}$ and $\mathrm{C}$ data hints at the fact that global atmospheric temperature fields on Venus did not significantly change over the last 23 Earth years that separate VIRTIS and PMV measurements.

Temperature values in the two last rows in Table 1 are extracted from D (Tellmann et al., 2009, Figure 10) and E (Piccially et al., 2012, Figure 2). They are based on data recorded during the Venus Express radiooccultation experiment VeRa (case D 
southern hemisphere, case E both hemispheres). A direct comparison with case A is difficult, however. Firstly, since there is much coarser vertical resolution in the VIRTIS data and secondly, since set D refers to different local times (not specified in the paper) at each latitude, while set $\mathrm{E}$ assumes local time independence based on a statement that temperature profiles do not show any significant trend due to local time. Absolute differences of temperatures A-D and A-E are much larger compared with $\mathrm{A}-\mathrm{B}$ and $\mathrm{A}-\mathrm{C}$, but temperatures $\mathrm{A}$ always lie between $\mathrm{D}$ and E values except for $30^{\circ} \mathrm{S} / 80 \mathrm{~km}$. The general features of the zonal average temperature field described above (e.g. position of the cold collar) are also well seen in $\mathrm{D}$ and $\mathrm{E}$ data.

\subsection{Cloud influence on temperature retrieval results}

The observed temperature variability between 55 and $80 \mathrm{~km}$ (especially at higher latitudes, cf. Figures 9 and 15) is associated with changes of cloud mode factors and cloud top altitude. VIRTIS measurements and corresponding simulations are very sensitive to cloud parameter changes, but the individual cloud mode contrasts (i.e. radiance and brightness temperature changes due to mode variations) are different with respect to wavelength (Haus and Arnold, 2010; Haus et al., 2013). Mode 2 particle contrasts clearly dominate in the $4.3 \mu \mathrm{m} \mathrm{CO}_{2}$ band wings, since the mode 2 altitude distribution function is assumed to peak at $65 \mathrm{~km}$ in the initial cloud model. $65-70 \mathrm{~km}$ is just the altitude range where the main contribution to the top-of-atmosphere radiance in the band wings comes from. Cloud contrasts disappear in the center region of the band where radiation originates from altitudes above 80 $\mathrm{km}$. The $4.3 \mu \mathrm{m}$ spectral range is almost not sensitive to mode 3 abundance changes, however, since the mode 3 altitude distribution function peaks between 48 and $56 \mathrm{~km}$ where temperature weighting functions become very small. The influence of mode 1 particles (the haze) is very small at infrared wavelengths, and possible abundance variations are combined with mode 2 variations by using the mode factor $\mathrm{MF}_{1,2}$, therefore. Based on these arguments, the correlation of thermal structure, cloud mode factor $\mathrm{MF}_{1,2}$, and cloud top altitude can be estimated from real retrievals. Recall that the utilized algorithm retrieves temperature profiles, cloud upper altitude boundaries, and cloud mode factors $\mathrm{MF}_{\mathrm{j}}$ in a self-consistent way where the latter two quantities determine the cloud top altitude.

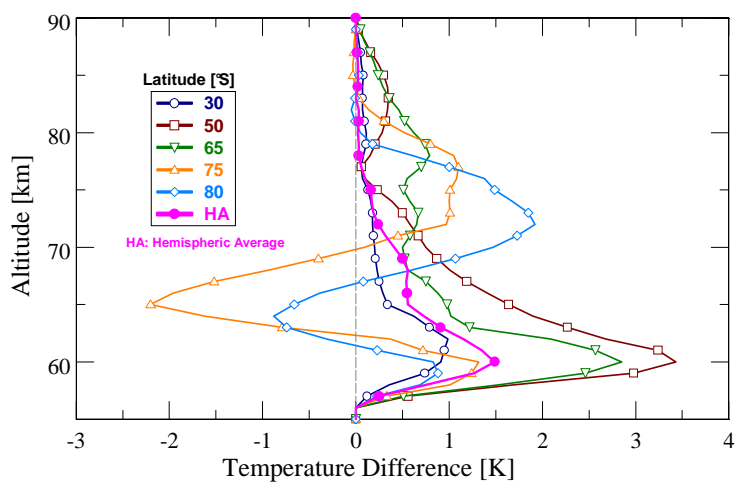

Figure 20. Differences of retrieved zonal average temperature profiles $\left(\Delta \mathrm{T}=\mathrm{T}_{\mathrm{n}}-\mathrm{T}_{\mathrm{c}}\right)$ when simultaneous cloud parameter retrievals are considered $\left(\mathrm{T}_{\mathrm{c}}\right)$ or neglected $\left(T_{n}\right)$.

Figure 20 shows the differences of retrieved zonal average temperature profiles at 30, 50, 65,75 , and $80^{\circ} \mathrm{S}$ when simultaneous cloud parameter retrievals are considered $\left(\mathrm{T}_{\mathrm{c}}\right)$ or neglected $\left(T_{n}\right)$ in the procedures. The displayed temperature change is defined by $\Delta \mathrm{T}=\mathrm{T}_{\mathrm{n}}-\mathrm{T}_{\mathrm{c}}$. Note that the hemispheric average (HA) curve is an average over all processed latitudes and local times and not only over the depicted curves. Retrieved and initial cloud parameters for the six selected cases are summarized in Table 2. Mesospheric temperature profiles at low and mid latitudes monotonically decrease with increasing altitude. Typical inversion (the cold collar) occurs at latitudes between 50 and $75^{\circ}$ and altitudes between 60 and $70 \mathrm{~km}$, while profiles become more isothermal in this altitude range poleward of $75^{\circ}$ (cf. Figures 7 and 12). As expected, retrieved temperatures decrease with decreasing mode factor $\mathrm{MF}_{1,2}$ and cloud top altitudes over the full altitude range at low and mid latitudes, since the retrieval algorithm compensates reduced cloud opacity by lower temperatures leading to positive $\Delta \mathrm{T}$ values. Different patterns of 
temperature change with reduced cloud top altitude (partly negative $\Delta \mathrm{T}$ values) are observed at latitudes poleward of about $50^{\circ}$, however, where the formation of inversion features in the near wings of the $4.3 \mu \mathrm{m}$ band (cf. Figure 6) depends on the specific interaction between cloud properties and thermal structure. Temperature variations associated with observed cloud parameter changes typically not exceed $2-3 \mathrm{~K}$ at altitudes between 60 and $75 \mathrm{~km}$ and are much smaller outside of this interval. Note however, that details in the depicted curves depend on the choice of the initial cloud model and that absolute temperature errors introduced by the retrieval algorithm are in the order of 1-1.5 K. Also recall that zonal average profile changes are shown here. Responses of retrieved temperatures to observed cloud parameter changes at fixed local times and high latitudes may become much more pronounced reaching maximum values of about $6 \mathrm{~K}$. Considering the strong temperature variability at latitudes southward of $60^{\circ} \mathrm{S}$ (cf. Figure 9), the overall influence of cloud parameter changes on the retrieved mesospheric zonal average temperature structure can be rated as rather moderate. This does not contradict the above statement that measured radiances are very sensitive to cloud parameter changes. Just this high sensitivity is the required precondition that temperature profile and cloud parameter influences on measured spectra are separable and appropriate self-consistent retrieval procedures can be used to allocate information on momentary as well as averaged upper and lower cloud features.

Table 2. Retrieved and initial cloud parameters related to Figure 20.

\begin{tabular}{cccc}
\hline Latitude $\left[{ }^{\circ} \mathrm{S}\right]$ & Mode factor $\mathrm{MF}_{1,2}$ & Mode factor $\mathrm{MF}_{3}$ & Cloud top altitude $[\mathrm{km}]$ \\
\hline 30 & 0.95 & 1.07 & 71.2 \\
50 & 0.71 & 1.09 & 69.9 \\
65 & 0.64 & 1.43 & 65.6 \\
75 & 0.51 & 2.00 & 62.4 \\
80 & 0.38 & 2.12 & 61.6 \\
\hline Hemispheric Average & 0.77 & 1.35 & - \\
\hline Initial values & 1.00 & 1.00 & 71.3 \\
\hline
\end{tabular}

\subsection{Thermal tides}

The different patterns of altitude, latitude, and local time dependent mesospheric temperature structure may be forced by thermal tides, which are generated by absorption of solar radiation on Venus' dayside mainly in the upper clouds. Their presence was recognized in OIR (Schofield and Taylor, 1983) and PMV (Zasova et al., 2006a; 2007) data in the northern hemisphere in terms of different components (diurnal or wavenumber-1, semi-diurnal or wavenumber-2, and even larger wavenumbers). Figure 21 illustrates the differences between local time dependent and local time averaged mean temperatures as functions of local time (solar longitude) for different latitudes and two altitudes $65 \mathrm{~km}$ (display a) and $80 \mathrm{~km}$ (display b), respectively. This figure corresponds to Figures $14 \mathrm{c}$ and $\mathrm{d}$, but temperature differences are now displayed onedimensionally for six selected latitudes. Such kind of plot makes the local time variations easier discernible.

As it was already discussed in the context of Figure 14, the atmosphere is warmer in the second half of night at altitudes above about $75 \mathrm{~km}$, while the dawn side at lower altitudes is usually colder than the dusk side. Present VIRTIS-M-IR analyses are restricted to nightside measurements. It is difficult to attribute observed patterns of temperature variability to the presence of distinct components of thermal tides when half of a full day is absent in the data. Based on 
accessible information shown in Figure 21, both at 65 and $80 \mathrm{~km}$, variability with solar longitude is mainly characterized by a diurnal (wavenumber-1) component with maximum amplitude of about $5 \mathrm{~K}$ and varying phase. Exceptions are observed at 65 $\mathrm{km} / 80^{\circ}$ and $80 \mathrm{~km} / 40$ and $70^{\circ} \mathrm{S}$ where the variability resembles more a semi-diurnal wave. This does not contradict the findings of Zasova et al. $(2006 a ; 2007)$ that at high latitudes and $55-72 \mathrm{~km}$ altitude wavenumber1 amplitudes exceed that of wavenumber-2, although wavenumber-2 dominated in many cases in OIR and PMV data. The specific phases and amplitudes of VIRTIS observations differ from Zasovas's results, however. A partly better agreement is found in comparison with results presented by Grassi et al. (2010) in their Figure 4. The authors however interpreted the maxima and minima found in the region of the southern cold collar $\left(65 \mathrm{~km} / 65^{\circ} \mathrm{S}\right)$ to be determined by effects of a semi-diurnal component of the thermal tide, may be by relating the wave definition erroneously to a $12 \mathrm{~h}$ period.

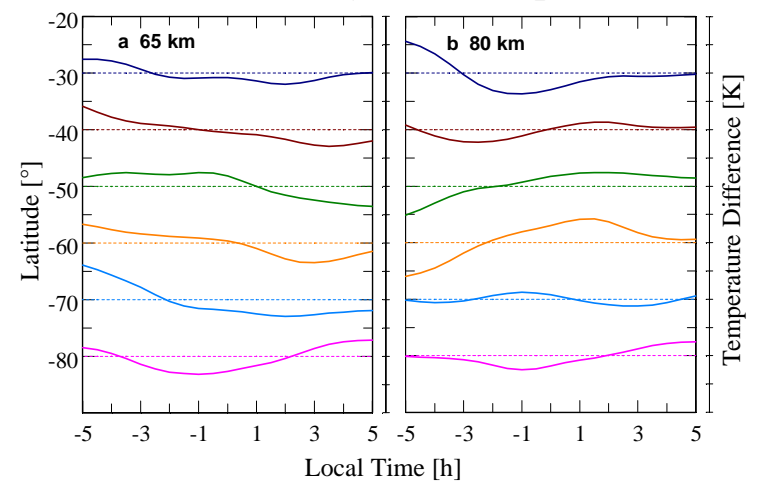

Figure 21. Differences between local time dependent and local time averaged mean temperatures as functions of local time for different latitudes at $65 \mathrm{~km}$ (a) and $80 \mathrm{~km} \mathrm{(b).} \mathrm{Each} \mathrm{tick} \mathrm{on} \mathrm{the} \mathrm{auxiliary} \mathrm{ordinate}$ scale on the right side of the displays corresponds to 5 K.

Figure 15 in the work of Tellmann et al. (2009), which is based on VeRa analyses, also suggests the dominance of the semidiurnal wave at averaged latitudes between 75 and $85^{\circ}$ and $60-64 \mathrm{~km}$ altitude. Present results shown in Figure 21 indicate the existence of a diurnal wave at $70^{\circ} \mathrm{S}$, but a more semi-diurnal wave structure near the pole. Summarizing this paragraph, it has to be concluded that the agreement between different data sources and resulting interpretations is not very good at present. An extension of VIRTIS-M-IR data analyses to dayside measurements would allow for a full Fourier analysis to determine thermal tides, and future experiments are also required.

\section{Summary and Outlook}

New methodical approaches for selfconsistent temperature profile and cloud parameter retrievals from VIRTIS-MIR/VEX nightside radiation measurements over the southern hemisphere of Venus are applied to investigate both the thermal structure and cloud features of the planet's atmosphere. Temperature and cloud influences on measured spectra are carefully separated to allow for explicit cloud parameter studies. A data selection strategy is developed that is especially useful for statistical exploration of massive data sets. Combined radiative transfer and multiwindow retrieval techniques simultaneously process information from different spectral ranges of an individual spectrum. Mesospheric temperature altitude profiles $(58-85 \mathrm{~km})$ are determined from $4.3 \mu \mathrm{m} \mathrm{CO}$ absorption band signatures, using Smith's relaxation method. Specific parts of the 4.3 $\mu \mathrm{m}$ band wings as well as of the deep atmosphere transparency window at $2.3 \mu \mathrm{m}$ are utilized to derive cloud parameters (cloud top altitude, mode abundance factors, opacity). A wavelength-dependent $\mathrm{CO}_{2}$ opacity correction is considered in the transparency windows.

Zonal averages of southern hemisphere temperature features are in very close correspondence with results for the northern hemisphere and give evidence of global N-S axial symmetry of atmospheric temperature structure. Results for both hemispheres well correspond to earlier results reported in the literature. The strong cold inversion layer (cold collar), which is located at latitudes between 50 and $75^{\circ}$ and altitudes between 58 and $70 \mathrm{~km}$, divides the atmosphere vertically. For fixed altitudes below the cold collar, 
temperature decreases with increasing latitude poleward of $30^{\circ}$, while it increases above $70 \mathrm{~km}$ poleward of $40-50^{\circ}$. Warmer and vertically nearly isothermal regions poleward of $75^{\circ}$ extend from 58 to $66 \mathrm{~km}$ and are associated with a strongly timedependent bright polar vortex. Collar and vortex regions exhibit the strongest temperature variability with standard deviations up to $8.5 \mathrm{~K}$ at $75^{\circ} \mathrm{S}$ and $63 \mathrm{~km}$. This may correspond to maximum absolute temperature variations larger than $30 \mathrm{~K}$. Much less absolute temperature variability of about $4 \mathrm{~K}$ is observed at low and mid latitudes. Zonal averages of retrieved temperature profiles at mid and high latitudes are in good correspondence with VIRA profiles, while somewhat lower temperatures are found at low latitudes.

The mesospheric temperature field strongly depends on local time. In the cold collar altitude region, the atmosphere is essentially warmer at early night and colder at late night by about $8 \mathrm{~K}$. Local minimum temperature of $220 \mathrm{~K}$ occurs at 03:00 h local time at $65 \mathrm{~km}$ and $60^{\circ} \mathrm{S}$. The temporal temperature trend reverses at higher altitudes. A warmer cell, however, is observed at early night equatorward of $45^{\circ} \mathrm{S}$. The temperature standard deviation $\sigma_{\mathrm{T}}$ is particularly large at $65 \mathrm{~km}$ and $75-80^{\circ} \mathrm{S}$ in the first two thirds of night and reaches maximum values of about $9 \mathrm{~K}$ near midnight. This is related to the presence of the strongly changing eye of the polar vortex. $\sigma_{\mathrm{T}}$ is also large in the region of the cold collar $(4 \mathrm{~K})$. Equatorial latitudes at $65 \mathrm{~km}$ and all latitudes at higher altitudes show significantly smaller temperature variability.

Mesospheric temperature variability with solar longitude seems to be forced by solar thermal tides with a dominating diurnal (wavenumber-1) component with maximum $5 \mathrm{~K}$ amplitude and varying phase. Semidiurnal components are also present. There are no explicit temperature trends with mission time. The averaged mesospheric thermal structure is essentially stable with Julian date between 2006 and 2008. The overall influence of cloud parameter changes on retrieved mesospheric zonal average temperature structure is moderate and does not exceed 2-3 $\mathrm{K}$ at altitudes between 60 and $75 \mathrm{~km}$.

VIRTIS-M-IR data for the southern hemisphere confirms a remarkable latitudinal dependence of cloud top altitude that has been previously derived by other authors but also from own analyses of northern hemisphere data. Zonal averages of cloud top altitudes in the southern hemisphere very closely match the northern results. There is a slow decrease of cloud top altitude at $1 \mu \mathrm{m}$ from about $71 \mathrm{~km}$ at the equator to about 70 $\mathrm{km}$ at $45-50^{\circ}$, but it quickly drops poleward of $50^{\circ}$ and reaches about $61 \mathrm{~km}$ over both poles. The average particle size in the vertical cloud column increases from mid latitudes toward the poles and also toward the equator. Hence, polar and equatorial latitudes are covered by thicker clouds than mid latitudes between 30 and $60^{\circ}$ in both hemispheres. Zonal average cloud opacities at $1 \mu \mathrm{m}$ in the southern hemisphere vary between 32.5 and 42.0. The planetary average is 36.5 . Both southern and northern hemispheric averages of cloud mode factors that scale modal altitude distributions of particle abundances of the initial model are about 0.75 for modes 1 and 2, and 1.35 for mode 3, respectively. Specific patterns of cloud top altitude and opacity variation with local time are very complex and strongly change with data acquisition time interval, while corresponding zonal averages are well compatible. Partly adverse features are observed in dependence on latitude that are due to perpetual changes of the cloud cover along with its superrotation around the planet. This also confirms the large variability of cloud morphology both on short and long time scales.

Future investigations will re-examine the variability of minor constituents in the lower atmosphere of Venus. Based on the new temperature, minor gas, and cloud maps, a specification of atmospheric net fluxes and cooling/heating rates will be performed that will eventually be used to obtain improved 
results on the radiative energy balance of Venus' middle and lower atmosphere. and local time for selected latitudes. Temperatures above about $84 \mathrm{~km}$ and below $56 \mathrm{~km}$ tend to follow initial VIRA profiles.

\section{Appendix}

Table 3 displays mean temperatures of the Venus mesosphere as functions of altitude

Table 3. Mean air temperatures as functions of altitude and local time for selected latitudes. z: altitude [km], LT: local time [h]. Note that first and last LT at $75^{\circ} \mathrm{S}$ are different from other latitudes due to lack of data coverage.

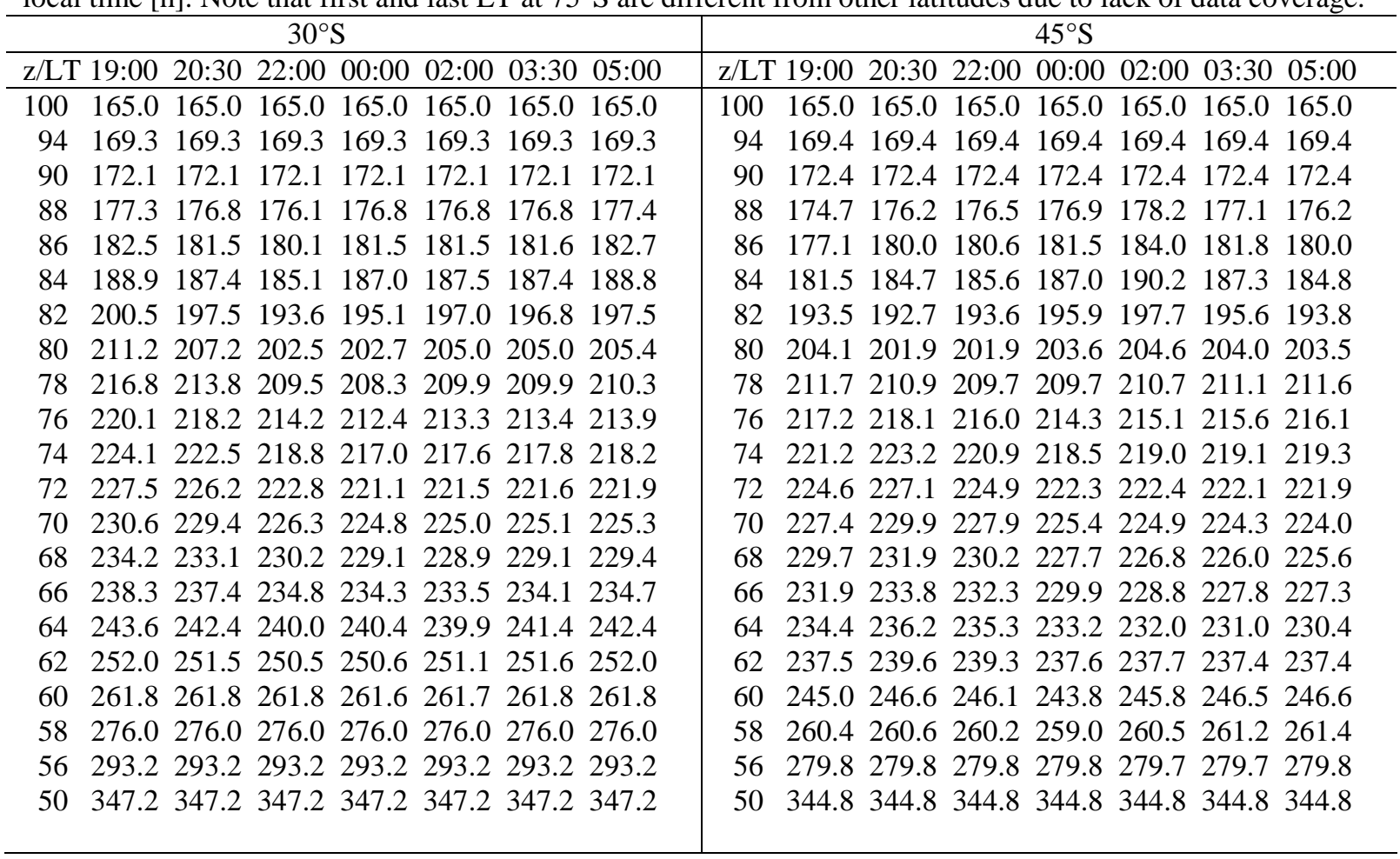

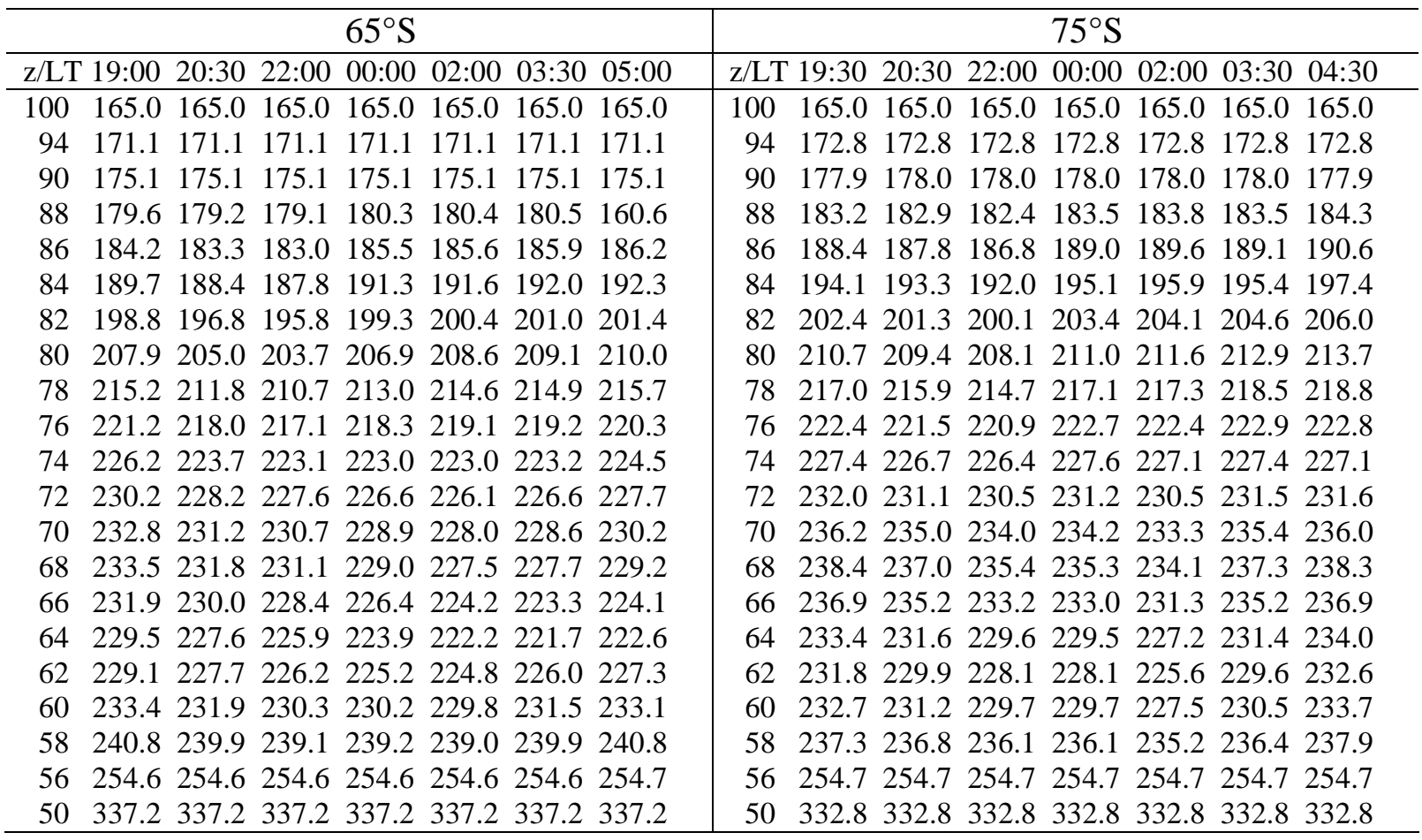




\section{Acknowledgements}

This work is funded by the German Research Foundation. We acknowledge the work of the VIRTIS/VEX team and also the entire Venus Express team of ESA and Astrium, who allowed the measurement data used in this investigation to be obtained.

\section{References}

Arnold, G., Haus, R., Kappel, D., Drossart, P., and Piccioni, G., 2008. Venus surface data extraction from VIRTIS/Venus Express measurements: Estimation of a quantitative approach. J. Geophys. Res. 13(E00B10), 13 pp., http://dx.doi.org/10.1029/2008JE003087.

Arnold, G., 2011. Exploring the solar system: the view of planetary surfaces with VIS/IR remote sensing methods. Proc. SPIE 8154, Infrared Remote Sensing and Instrumentation XIX, 815402, http://dx.doi.org/10.1117/12.897759.

Arnold, G., Drossart, P., Piccioni, G., and Haus, R., 2011. Venus atmospheric and surface studies from VIRTIS on Venus Express. Proc. SPIE 8154, Infrared Remote Sensing and Instrumentation XIX, 81540W, http://dx.doi.org/10.1117/12.892895.

Arnold, G., Haus, R., Kappel, D., Piccioni, G., and Drossart, P., 2012. VIRTIS/VEX observations of Venus: Overview of selected scientific results. J. Appl. Remote Sensing 6, 20 pp., http://dx.doi.org/10.1117/1.JRS.6.063580.

Carlson, R.W., and Anderson, M.S., 2011, Absorption properties of sulfuric acid in Venus' infrared spectral window region. EPSC Abstracts 6,1171 .

Cottini, V., Ignatiev, N.I., Piccioni, G., Drossart, P., Grassi, D., and Markiewicz, W.J., 2012.

Water vapor near the cloud tops of Venus from Venus Express/VIRTIS dayside data. Icarus 217(2), 561-569, http://dx.doi.org/10.1016/j.icarus.2011.06.018.

Drossart, P., Piccioni, G., Adriani, A., Angrilli, F., Arnold, G. et 39 al., 2007. Scientific goals for the observation of Venus by VIRTIS on ESA/Venus express mission. Planet. Space Sci. 55(12), 1653-1672,

http://dx.doi.org/10.1016/j.pss.2007.01.003.
Grassi, D., Migliorini, A., Montabone, L., Lebonnois, S., Cardesin-Moinelo et 3 al., 2010. Thermal structure of Venusian nighttime mesosphere as observed by VIRTIS-Venus Express. J. Geophys. Res. 115 (E09007), 11 pp., http://dx.doi.org/10.1029/2009JE003553.

Grinspoon, D.H., Pollack, J.B., Sitton, B.R., Carlson, R.W., Kamp, L.W. et 3 al., 1993. Probing Venus's cloud structure with Galileo NIMS. Planet. Space Sci. 41(7), 515-542, http://dx.doi.org/10.1016/0032-0633(93)90034-Y.

Haus, R. and Titov, D.V., 2000. PFS on Mars Express: Preparing the analysis of infrared spectra to be measured by the Planetary Fourier Spectrometer. Planet. Space Sci. 48(12-14), 1357-1376, http://dx.doi.org/10.1016/S0032-0633(00)00116-1.

Haus, R., 2002. Development of multispectral atmospheric retrieval software for application to the atmosphere of Mars. Adv. Space Res. 29(2), 163-167,

http://dx.doi.org/10.1016/S0273-1177(01)00565-8.

Haus, R. and Arnold, G., 2010. Radiative transfer in the atmosphere of Venus and application to surface emissivity retrieval from VIRTIS/VEX measurements. Planet. Space Sci. 58(12), 15781598 ,

http://dx.doi.org/10.1016/j.pss.2010.08.001.

Haus, R., Kappel, D., and Arnold, G., 2013. Selfconsistent retrieval of temperature profiles and cloud structure in the northern hemisphere of Venus using VIRTIS/VEX and PMV/VENERA15 radiation measurements. Planet. Space Sci. 89, 77-101, http://dx.doi.org/10.1016/j.pss.2013.09.020.

Ignatiev, N.I., Titov, D.V., Piccioni, G., Drossart, P., Markiewicz, W.J. et 4 al., 2009. Altimetry of the Venus cloud tops from the Venus Express observations. J. Geophys. Res. 114(E00B43), 10 pp., http://dx.doi.org/10.1029/2008JE003320.

Kappel, D., Arnold, G., Haus, R., Piccioni, G., and Drossart, P., 2012. Refinements in the data analysis of VIRTIS-M-IR Venus nightside spectra. Adv. Space Res. 50(2) 228-255, http://dx.doi.org/10.1016/j.asr.2012.03.029.

Kappel, D., 2014. MSR, a multi-spectrum retrieval technique for spatially-temporally correlated or common Venus surface and 
atmosphere parameters. J. Quant. Spectrosc. Rad. Transfer 133, 153-176, http://dx.doi.org/10.1016/j.jqsrt.2013.07.025.

Kappel, D., Haus, R., and Arnold, G., 2014. Error analysis for retrieval of Venus' IR surface emissivity from VIRTIS/VEX measurements. Submitted to J. Quant. Spectrosc. Rad. Transfer.

Lee, Y.J., Titov, D.V., Tellmann, S., Piccialli, A., Ignatiev, N. et 4 al., 2012. Vertical structure of the Venus cloud top from the VeRa and VIRTIS observations onboard Venus Express. Icarus 217(2), 599-609,

http://dx.doi.org/10.1016/j.icarus.2011.07.001.

Limaye, S.S, Kossin, J.P., Rozoff, C., Piccioni, G., Titov, D.V., and Markiewicz, W.J., 2009. Vortex circulation on Venus: Dynamical similarities with terrestrial hurricanes. Geophys. Res. Letters, 36,(4), 204, http://dx.doi.org/10.1129/2008GL036093.

Luz, D., Berry, D.L., Piccioni, G., Drossart, P., Politi, R. et 3 al., 2011. Venus's southern polar vortex reveals precessing circulation. Science 332(6029), 577-580,

http://dx.doi.org/10.1126/science.1201629.

Marcq, E., Belyaev, D., Montmessin, F., Fedorova, A., Bertaux, J.L. et 2 al., 2011. An investigation of the $\mathrm{SO}_{2}$ content of the Venusian mesosphere using SPICAV-UV in nadir mode. Icarus 211(1), 58-69,

http://dx.doi.org/10.1016/ j.icarus.2010.08.021.

Marcq, E., Bertaux, J.L., Montmessin, F., and Belyaev, D., 2013. Variations of sulphur dioxide at the cloud top of Venus's dynamic atmosphere. Nature Geoscience 6, 25-28, http://dx.doi.org/10.1038/ngeo1650.

Palmer, K.F., and Williams, D., 1975. Optical constants of sulphuric acid: Application to the clouds of Venus. Appl. Opt. 14(1), 208-219, http://dx.doi.org/10.1364/AO.14.000208.

Piccialli, A., Tellmann, S., Titov, D.V., Limaye, S.S., Khatuntsev, I.V. et al., 2012. Dynamical properties of the Venus mesosphere from the radio-occultation experiment $\mathrm{VeRa}$ onboard Venus Express. Icarus 217(2), 669-681, http://dx.doi.org/10.1016/j.icarus.2011.07.016.

Piccioni, G., Drossart, P., Suetta, E., Cosi, M., Ammannito, E. et 61 al., 2007a. VIRTIS: The
Visible and Infrared Thermal Imaging Spectrometer, ESA Spec. Publ. SP-1295, pp. 1 27, European Space Agency, Paris.

Piccioni, G., Drossart, P., Sanches-Lavega, A., Hueso, R., Taylor, F.W. et 39 al., 2007b. Southpolar features on Venus similar to those near the north pole. Nature 450, 637-640, http://dx.doi.org/10.1038/nature06209.

Pollack, J.B., Dalton, J.B., Grinspoon, D., Wattson, R.B., Freedman, R. et 7 al., 1993. Nearinfrared light from Venus' nightside: A spectroscopic analysis. Icarus 103(1), 1-42, http://dx.doi.org/10.1006/icar.1993.1055.

Schofield, J.T. and Taylor, F.W., 1983. Measurements of the mean, solar-fixed temperature and cloud structure of the middle atmosphere of Venus. Q. J. R. Meteorol. Soc. 109, 57-80, http://dx.doi.org/10.1002/qj.49710945904.

Seiff, A. and Kirk, D.B., 1982. Structure of the Venus mesosphere and lower thermosphere from measurements during entry of the Pioneer Venus probes. Icarus 49(1), 49-70, http://dx.doi.org/10.1016/0019-1035(82)90056-2.

Seiff, A., Schofield, J.T., Kliore, A.J., Taylor, F.W., Limaye, S.S. et 5 al., 1985. Models of the structure of the middle atmosphere of Venus from the surface to 100 kilometers altitude. In: The Venus International Reference Atmosphere, Kliore, A. J., Moroz, V.I., Keating, G.M. (Eds.), Adv. Space Res. 5(11), 1-305 (1985),

http://dx.doi.org/10.1016/0273-1177(85)90197-8.

Smith, W.L., 1970. Iterative solution of the radiative transfer equation for the temperature and absorbing gas profile of an atmosphere. Appl. Opt. 9(9), 1993-1999,

http://dx.doi.org/10.1364/AO.9.001993.

Stamnes, K., Tsay, S.C., Wiscombe, W., and Jayaweera, K., 1988 . Numerically stable algorithm for discrete-ordinate-method radiative transfer in multiple scattering and emitting layered media. Appl. Opt. 27(12), 2502-2509, http://dx.doi.org/10.1364/AO.27.002502.

Taylor, F.W., Diner, D.J., Elson, L.S., McCleese, D.J., Martonchik, J.V., Delderfield, J., Bradley, S.P., Schofield, J.T., Gille, J.C., and Coffey, M.T., 1979. Temperature, cloud structure, and dynamics of Venus middle atmosphere by 
infrared remote-sensing from Pioneer Orbiter. Science 205(4401), 65-67, http://dx.doi.org/10.1126/science.205.4401.65.

Taylor, F.W., Beer, R., Chahine, M.T., Diner, D.J., Elson, L.S. et 12 al., 1980. Structure and meteorology of the middle atmosphere of Venus: Infrared remote sensing from the Pioneer orbiter. J. Geophys. Res. 85(A13), 7963-8006, http://dx.doi.org/10.1029/JA085iA13p07963.

Tellmann, S., Pätzold, M., Häusler, B., Bird, M.K., and Tyler, G.L., 2009. Structure of the Venus neutral atmosphere as observed by the Radio Science experiment $\mathrm{VeRa}$ on Venus Express. J. Geophys. Res. 114(E00B36), 354372, http://dx.doi.org/10.1029/2008JE003204.

Titov, D.V., Svedhem, H., Taylor, F.W., Barabash, S., Bertaux, J.L. et 16 al., 2009. Venus Express: Highlights of the nominal mission. Solar System Research 43(3), 185-209, http://dx.doi.org/10.1134/S0038094609030010.

Titov, D.V., Markiewicz, W.J., Ignatiev, N.I., Song, L., Limaye, S.S. et 12 al., 2012. Morphology of the cloud tops as observed by the Venus Express Monitoring Camera. Icarus 217(2), 682-701, http://dx.doi.org/10.1016/j.icarus.2011.06.020.

Wilson, C.F., Guerlet, S., Irwin, P.G.J., Tsang, C.C.C., Taylor, F.W., et 3 al., 2008. Evidence for anomalous cloud particles at the poles of Venus. J. Geophys. Res. 113(E00B13), 373-384, http://dx.doi.org/10.1029/2008JE003108.

Wiscombe, W.J., 1980. Improved Mie scattering algorithms. Appl. Opt. 19(9), 1505-1509, http://dx.doi.org/10.1364/AO.19.001505.

Zasova, L.V., Moroz, V.I., Formisano, V., Ignatiev, N.I., and Khatuntsev, I.V., 2006a. Exploration of Venus with the Venera-15 IR Fourier Spectrometer and the Venus Express Planetary Fourier Spectrometer. Cosmic Res. 44(4), 349-363,

http://dx.doi.org/10.1134/S0010952506040083.

Zasova, L.V., Moroz, V.I., Linkin, V.M., Khatuntsev, I.V., and Maiorov, B.S., 2006 b. Structure of the Venusian atmosphere from surface up to $100 \mathrm{~km}$. Cosmic Res. 44(4), 364383, http://dx.doi.org/10.1134/S0010952506040095.
Zasova, L.V., Ignatiev, N.I., Khatuntsev, I., and Linkin, V., 2007. Structure of the Venus atmosphere. Planet. Space Sci. 55(12), 17121728,http://dx.doi.org/10.1016/j.pss.2007.01.011. 